\title{
ACTIVIDAD TURÍSTICA EN CARTAGENA (MURCIA) A TRAVÉS DEL ANÁLISIS DE INDICADORES Y PERCEPCIÓN DE SUS ACTORES DIRECTOS
}

\author{
María José Jiménez Meseguer* \\ Centro Asociado Universidad Nacional de Educación a Distancia. Cartagena. España
}

Francisco José Morales Yago**

Universidad Nacional de Educación a Distancia

\section{RESUMEN}

La Recuperación del patrimonio cultural, natural y paisajístico de la ciudad de Cartagena constituyen un elemento clave en el desarrollo local de esta ciudad, así como un cambio en el modelo de desarrollo económico tradicionalmente dedicado principalmente al sector industrial, militar y portuario. En la actualidad la preponderancia del turismo como actividad dinamizadora está generando la creación de muchos puestos de trabajo tanto en la atención directa a los visitantes como a la necesidad de recuperar y mostrar un patrimonio cultural en muchos casos oculto desde hace siglos. El presente trabajo ofrece desde el uso estadístico de indicadores básicos y el propio análisis de encuesta, datos clarificadores sobre la actividad turística actual en Cartagena.

Palabras clave: paisaje; turismo, desarrollo local, valorización de recursos territoriales.

\section{Tourist activity in Cartagena (Murcia), through the perception and analysis of its} direct actors

\section{ABSTRACT}

The recovery of the cultural, natural and landscape heritage of the city of Cartagena is a key element in the local development of this city, as well as a change in the model of economic development traditionally dedicated mainly to the industrial, military and port sectors. At present, the preponderance of tourism as a dynamic activity is generating the creation of many jobs both in the direct attention to visitors and the need to recover and show a cultural

Fecha de recepción: 18 de febrero de 2018

Fecha de aceptación: 27 de junio de 2018

*Calle Ingeniero de la Cierva, 28. 30203 CARTAGENA. Murcia (España).E-mail: jmmariajoo@gmail.com

**Paseo Senda del Rey, 7. 28040 MADRID (España). E-mail: fjmorales@ geo.uned.es 
heritage in many cases hidden for centuries. The present work offers, from the statistical use of basic indicators and the own analysis of the survey, clarifying data about the current tourist activity in Cartagena.

Keywords: landscape, tourism, Local Development, economic diversification.

\section{INTRODUCCIÓN}

El turismo se ha convertido en una de las principales fuentes de ingreso en España, conviviendo en nuestra ciudad objeto de estudio el turismo de sol y plaza, y turismo cultural (García Pérez, 2003). El turismo cultural ha crecido en las últimas décadas, ligado con los nuevos modelos de comportamiento turístico (Herrero, 2000), y está adquiriendo cada vez una mayor representación dentro de la economía cartagenera, a pesar de la crisis económica la el turismo de la ciudad no se ha visto tan afectado (Martín y Timón, 2006). Frente a la percepción que se tenía del turismo como una actividad muy variable, este cada vez va adquiriendo una mayor importancia y solidez. La Región de Murcia, y por ende Cartagena han experimentado uno de los mayores crecimientos de la actividad turística desde comienzos de siglo (Vera, 2005).

Cartagena es una ciudad situada al sur de la Región de Murcia, que alberga una población de-superior a los 200.000 habitantes, lo que la convierte en la segunda ciudad más grande de esta Comunidad Autónoma. La ciudad se fundó en un enclave geográfico en torno al Mediterráneo. Este contacto provocó influyó en el desarrollo de la ciudad como un enclave comercial (Andrés, 1982) y estratégico de las civilizaciones del mundo antiguo (Morales, 2016). El paso de las diferentes civilizaciones por la ciudad y su posterior puesta, pues hasta hace unas décadas la actividad económica se basó en la minería, la industria y la presencia del ejército (Andrés, 1989). La quiebra de ese modelo económico debido a la crisis del petróleo, se produjo a partir de 1970, lo que sumió a la ciudad en una profunda crisis provocando la degradación de los espacios centrales de la ciudad (Grandal, 2010). A partir de 1990 su modelo económico comenzó a cambiar, debido a la recuperación de los valores culturales, la puesta en valor del patrimonio y su aprovechamiento provocaron una recuperación de la ciudad que se está orientando hacia el desarrollo económico generado por la actividad turística (Morales, 2016), a pesar de que siempre ha existido una conciencia colectiva acerca de la riqueza que poseía la ciudad ante su antigüedad que abarca tres milenios (Soler, 2004)

En los últimos años, Cartagena se ha convertido en un referente de desarrollo local basado en la recuperación del patrimonio cultural (De la Calle y García, 2016) y su aprovechamiento turístico, siendo el patrimonio la principal razón de transformación urbana en las últimas décadas (Martínez, 1996). También ha sido notorio el gran esfuerzo inversor que las instituciones públicas han realizado para que la ciudad se convirtiese en una urbe adaptada y renovada (Morales, 2016). La proximidad a espacios destacados por el turismo de "sol y playa" como la ribera del Mar Menor, La Manga, así como espacios más alejados 
como la costa almeriense y la alicantina han provocado la atracción de visitantes interesados por una oferta patrimonial, cultural y paisajística de la ciudad (ICOMOS, 2010).

La ciudad de Cartagena recibe gran cantidad de turistas provenientes de las zonas costeras limítrofes que interrumpen sus vacaciones de sol y playa para acercarse al entorno cultural de la ciudad, pero que vuelven en la noche a sus alojamientos fuera de la ciudad (Galiana y Barrado, 2006). Lo que ha provocado un aumento de las plazas hoteleras, una mejora de su calidad y una importante remodelación con el objetivo de fomentar un mayor índice de permanencia de los visitantes (Galiana y Barrado, 2006). El desarrollo del turismo cultural es de reciente creación, lo que ha provocado que en tan sólo una década se haya duplicado el número de oferta hotelera, y una mejora en la creación de las infraestructuras (Vera, 2005). Esta renovación y diferenciación de los tradicionales destinos turísticos de sol y playa, se ha debido también a la mejora de la imagen de la ciudad y al descubrimiento y rehabilitación del patrimonio oculto de la ciudad convirtiéndose en un nuevo destino turístico (Antón, 2004) sin llegar a la dimensión de las actuales ciudades patrimonio de la Humanidad (Troitiño, M. 2009) y (Troitiño, L. 2014).

El éxito de la actividad turística estará garantizado cuando se supere la estacionalidad (Vera 2005), por lo que se deberán realizar estrategias de competitividad turística con la intención de atraer clientes (Foronda y García, 2009), convirtiendo de esta manera el turismo en una estrategia económico-territorial de la ciudad de Cartagena, tomando la administración como referencia medidas en pos de la sostenibilidad y la competitividad del sector (Vera, 2005). Estas estrategias de desarrollo turístico han tomado como medida principal una apuesta por la calidad y diferenciación de sus productos para la atracción de turistas, así como la renovación de su patrimonio y la mejora paisajística (Foronda y García, 2009) y la sostenibilidad turística (García Hernández, 2000).

Tradicionalmente, los destinos han sido un lugar concreto, pero en la actualidad se percibe como un conjunto de cosas como la formación cultural, el nivel educativo, el paisaje o el patrimonio (Bigné, Font y Andreu, 2000). Los recursos turísticos y servicios que existen dentro de este lugar deben satisfacer las necesidades turísticas de los visitantes que condicionarán futuras visitas, ya que este la experiencia de los mismos se basa en la relación que tienen con los museos, zonas verdes, recursos territoriales, patrimonio, etc. (Bigné, Font y Andreu, 2000).

En la actualidad, algunos destinos turísticos emplean el marketing, como si de un producto se tratase, a través de la comunicación, las notas de prensa, la publicidad y las creencias comunes (Bigné, Font y Andreu, 2000). La atención adecuada a los turistas se basa en la existencia de infraestructura y servicios, pero que no pueden amenazar la integridad de los recursos patrimoniales de la ciudad, ni las necesidades de la población residente en el lugar (Bosque, 1995). El desarrollo de las infraestructuras de servicios pueden afectar a los bienes a los que pretenden servir debido a la complejidad de las infraestructuras actuales (Bosque, 1995).

\section{UNA INFRAESTRUCTURA HOTELERA EN PLENO DESARROLLO}

Los establecimientos de alojamientos, además de permitir el alojamiento de las personas, actúan como distribuidores de productos y servicios turísticos, como visitas a museos, 
o a zonas próximas, de esta misma manera ocurre en Cartagena (Bigné, Font y Andreu, 2000). El número de viajeros en los hoteles y las pernoctaciones está aumentando en las últimas décadas, llegando la tasa media de ocupación de Cartagena hasta el $80 \%$ de las pernoctaciones de viajeros en 2015 (Martínez, 2015).

\subsection{Ocupación hotelera}

Tal y como vemos en la figura 1 a partir del año 2002, en el comienzo del "boom" inmobiliario, existen pequeñas plazas hoteleras y de poca capacidad. La mayoría de plazas hoteleras, $50 \%$, pertenecen a hoteles de cuatro estrellas, situándose en torno a las 700 plazas hoteleras; además si nos fijamos entre los años 2003 y 2010 no damos cuenta de cómo las plazas hoteleras han ido aumentando hasta las 1200 plazas. Por otro lado, entre 2011 y 2012 se puede observar un aumento descomunal de las plazas hoteleras de estrellas, ocupando el $60 \%$ de todas las plazas hoteleras, lo que las situaría en torno a las 3700 plazas. Mientras que a partir de 2013 podemos ver cómo las plazas hoteleras vuelven a ocupar el $50 \%$ en cuanto a hoteles de 4 estrellas, 1400 plazas, y el $30 \%$ en cuanto a hoteles de 3 estrellas, entre 700 y 800 plazas. Se ha de explicar que se ha centrado el análisis en relación a las plazas hoteleras de hoteles de tres y cuatro estrellas debido a que son las que han sufrido un aumento más importante.

\section{Figura 1 \\ EVOLUCIÓN DE PLAZAS HOTELERAS SEGÚN CATEGORÍAS EN CARTAGENA}

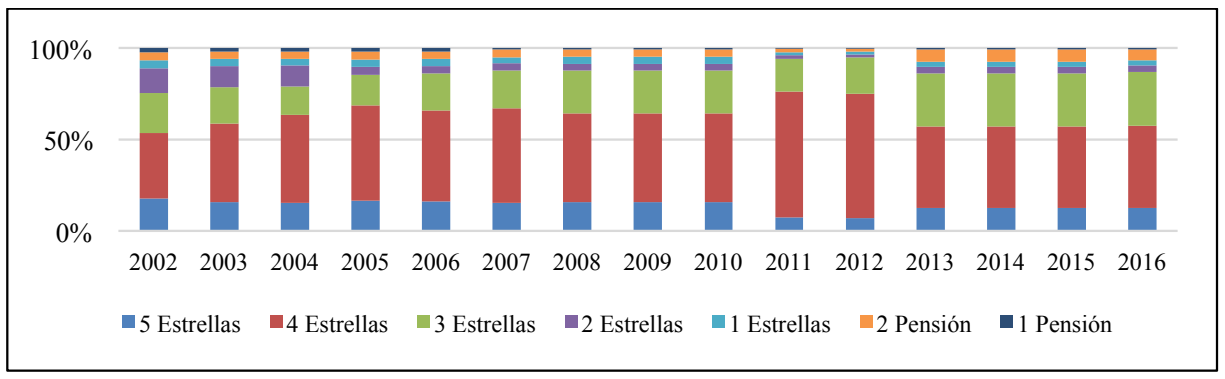

Fuente: Elaboración propia a través de datos de la Comunidad Autónoma de la Región de Murcia.

En resumen, las plazas hoteleras de Cartagena se centra en un turismo más especializado, para turistas que poseen un cierto nivel adquisitivo, pero que a partir de 2013 ha descendido, no sólo debido a la crisis existente, sino también a que se han demolido gran cantidad de edificios degradados, y otros se encuentran en rehabilitación y remodelación lo que provoca que descienda el número de plazas pero que posteriormente volverán a estar en funcionamiento debido a la rehabilitación de hoteles y hostales antiguos. 


\section{Figura 2 \\ EVOLUCIÓN DEL NÚMERO DE ESTABLECIMIENTOS HOTELEROS}

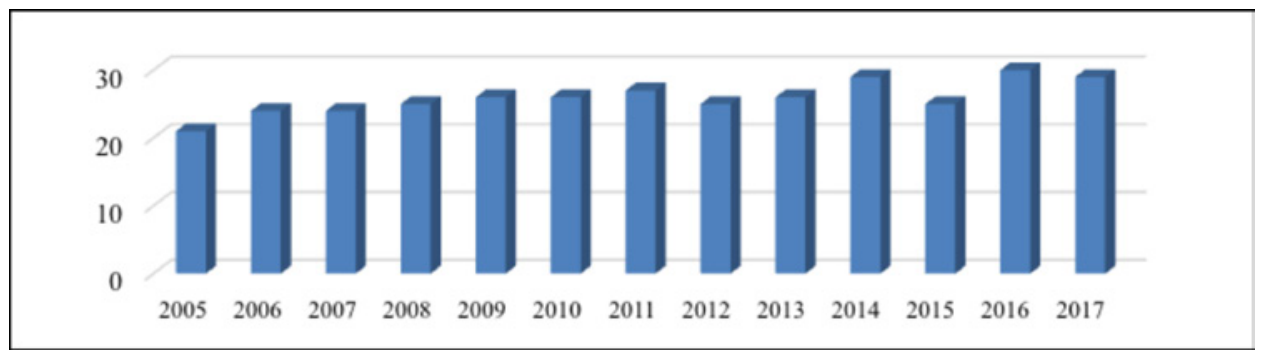

Fuente: Elaboración propia a través de datos del Instituto Nacional de Estadística.

En la figura 2, se puede observar que a pesar de que el número de plazas hoteleras no haya aumentado significativamente tal y como vemos en la figura 3 , sí que ha ido aumentando de manera lenta pero progresiva el número de establecimientos hoteleros abiertos. Se ha pasado de tener veintiún establecimientos en 2005 hoteleros hasta veintinueve en 2017, por lo que el aumento ha sido de un $38,09 \%$ en doce años.

\section{Figura 3 \\ EVOLUCIÓN DEL NÚMERO DE PLAZAS ESTIMADAS}

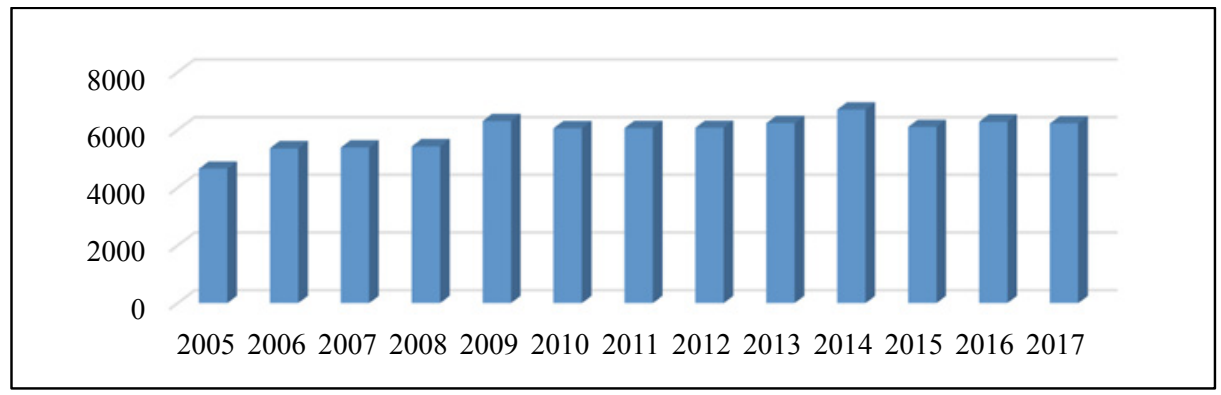

Fuente: Elaboración propia a través de datos del Instituto Nacional de Estadística.

En la figura 4, podemos ver cómo ha evolucionado el número de plazas estimadas. Se observa que al igual que en el gráfico anterior, la evolución del número de plazas estimadas ha sido importante y a que ha tenido un crecimiento progresivo pero no muy destacado; se percibe cómo se ha pasado en 2005 de tener un poco menos de 5000 plazas estimadas, hasta tener en 2017 alrededor de 6000, mostrando el año de su mayor incremento, 2014, un total de 6500 plazas estimadas.

Se puede observar la evolución tanto del grado de ocupación por plazas hoteleras, y la evolución del grado de ocupación por apartamentos en fines de semana. Se puede ver las diferencias que hay entre los diferentes años no es muy importante. En 2005, en ambos 
gráficos, se puede observar cómo las diferencias entre los diferentes años no resultan demasiado importantes. En los años 2005, 2006 y 2007 se aprecia una mayor importancia, mientras que en los años intermedios existe un menos porcentaje de la ocupación tanto de las plazas hoteleras como de los apartamentos. Esto es debido sobre todo a la época de crisis que no azotó únicamente a España, sino también a la unión europea, principal emisora de turistas para Cartagena, pero a partir de 2015 y hasta nuestros días se puede atestiguar cómo el grado de ocupación tanto en hoteles como en pensiones podemos ver cómo su ocupación ha aumentado notablemente, esto es debido a que actualmente la Unión europea está saliendo de la crisis económica.

\section{Figura 4 \\ EVOLUCIÓN DEL PERSONAL EMPLEADO EN LOS ESTABLECIMIENTOS HOTELEROS}

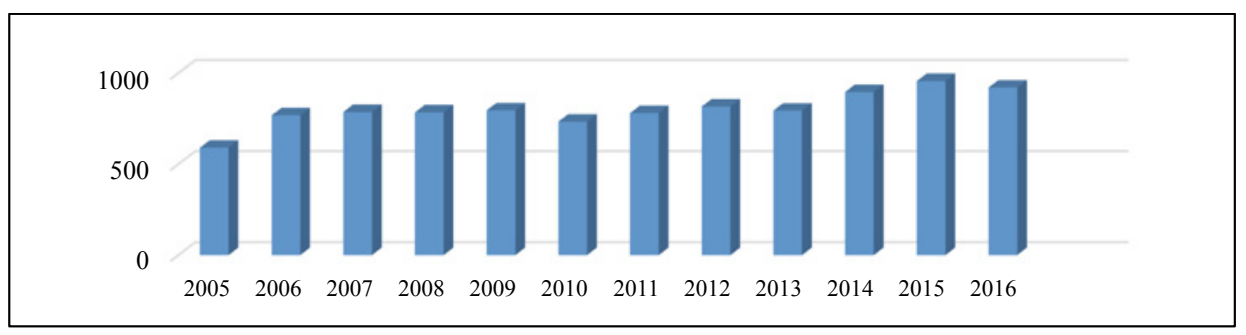

Fuente: Elaboración propia a través de datos del Instituto Nacional de Estadística.

Finalmente se puede observar cómo se ha producido un aumento progresivo del personal empleado, se ha pasado de los casi 600 empleos en 2005 hasta los 800 en 2017, a pesar de que en 2015 se encuentra la cuota más alta alrededor de 900 empleos descendiendo hasta 2017. El número de empleos en Cartagena ha ido en aumento debido a la importancia que ha ido adquiriendo el turismo en la ciudad de Cartagena, y que continuará ampliándose progresivamente en función del aumento de la importancia del turismo.

\subsection{Procedencia y estancia media}

En cuanto al análisis del turismo de Cartagena, también resulta importante destacar los lugares de procedencia de los turistas, así como la evolución de la estancia media para poder así extraer debilidades u oportunidades de cara a establecer unas perspectivas de futuro respecto al mismo. Por norma general, el turista que se acerca a visitar la ciudad suele proceder de otro punto de España (Andalucía, C. la Mancha, C. Valenciana y C. y León), o ser turistas extranjeros (Reino Unido, Alemania, Italia y Bélgica), aunque más adelante se comentará en profundidad. En cuanto a la edad, destacan las personas situadas entre los 36 y 45 años de edad, y que viaja sobre todo en pareja o con la familia. En cuanto a la llegada a la ciudad, suele hacerlo en coche particular en el caso de turistas españoles, o a través del avión o el barco en cuanto a turistas extranjeros. Estos turistas no vienen solo 
el busca del turismo de sol y playa, sino también por la gastronomía, el ocio nocturno, la naturaleza, el comercio, etc. con una media de 61`40 $€$ por persona y día.

\section{Figura 5 \\ ESTANCIA MEDIA DE DÍAS DE LOS TURISTAS}

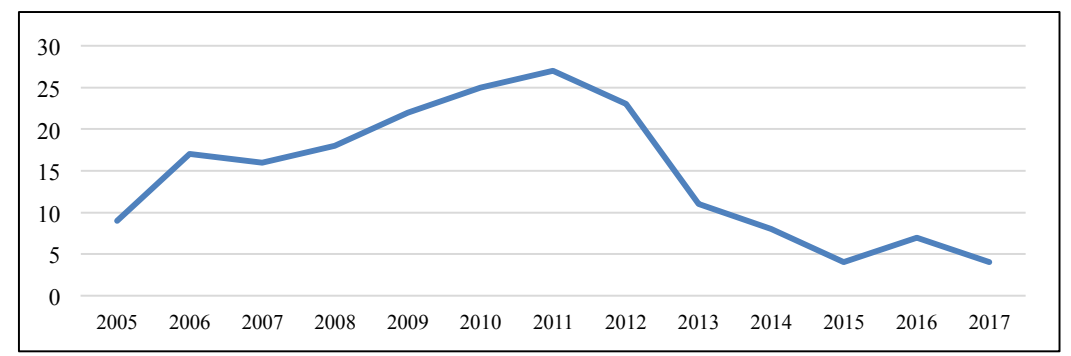

Fuente: Elaboración propia a través de datos del Instituto Nacional de Estadística.

Tal y como vemos en la figura 5, el número de días de estancia media se va reduciendo a lo largo de los años. En 2005, la estancia media era de 9 días, ya que era turismo de sol y playa principalmente, y de los cuales 1 o 2 se dedicaban a visitar la ciudad. Durante la época de crisis esto se fue reduciendo, para volver a aumentar a partir de 2007, en el cual se estimaba una media de 15 días hasta 2012 donde encontramos un total de casi 30 días de estancia media, en los que se producía un turismo de sol y playa y de los cuales 1 o 2 se dedicaban a visitar la ciudad. A partir de 2012 la estancia media se ha ido reduciendo, no porque los turistas vengan un menor número de días, sino que se ha incrementado el número de turistas y sobre todo el número de ellos que viene únicamente a realizar turismo cultural, por lo que este tipo de turismo ha hecho que aumente la ponderación llegando a situarse en una estancia media de 4 días. Se ha de destacar que el mayor número de viajeros pertenece a R. Unido, EE.UU, Alemania e Italia, que aportan la mayor cantidad de turistas debido a sus recursos económicos.

\section{Figura 6 \\ EVOLUCIÓN DE LOS VIAJEROS POR PROCEDENCIA}

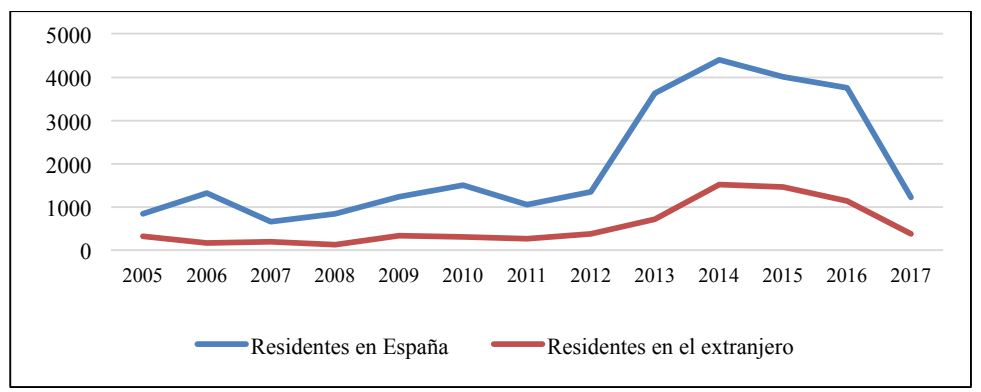

Fuente: Elaboración propia a partir de datos de ECONET. 
Tal y como se puede analizar en la figura 6, se puede analizar la evolución de los turistas que han llegado a la ciudad de Cartagena. En cuanto a la procedencia, podemos ver cómo existe una mayor cantidad de turistas nacionales que llegan a la ciudad y cuya cantidad ha aumentado de forma exponencial en los últimos años, mientras que los turistas extranjeros han sufrido un aumento más paulatino. En cuanto a la evolución de la población extranjera, entre los años 2005 a 2007 se prevé un incremento del número de turistas nacionales, pasando de los 700 turistas a los 1400, pero que con la llegada de la crisis en 2007 desciende hasta los 600 turistas. Durante este periodo de crisis, es decir, desde 2007 a 2012 el número de turistas españoles va en aumento pero de forma muy lenta y progresiva hasta el año 2012. A partir de este años se produce un incremento relevante situándose en 4.700 personas en 2016.

Por otro lado, tenemos a la población extranjera, que va aumentando progresivamente hasta 2013; a partir del mismo se observa un crecimiento más importante a partir de 2013, hecho que seguirá aumentando debido a la buena progresión turística de la ciudad y al aumento del turismo de cruceros.

\section{Figura 7 \\ NÚMERO DE VIAJEROS NACIONALES EN LA CIUDAD CARTAGENA, LORCA Y MURCIA}

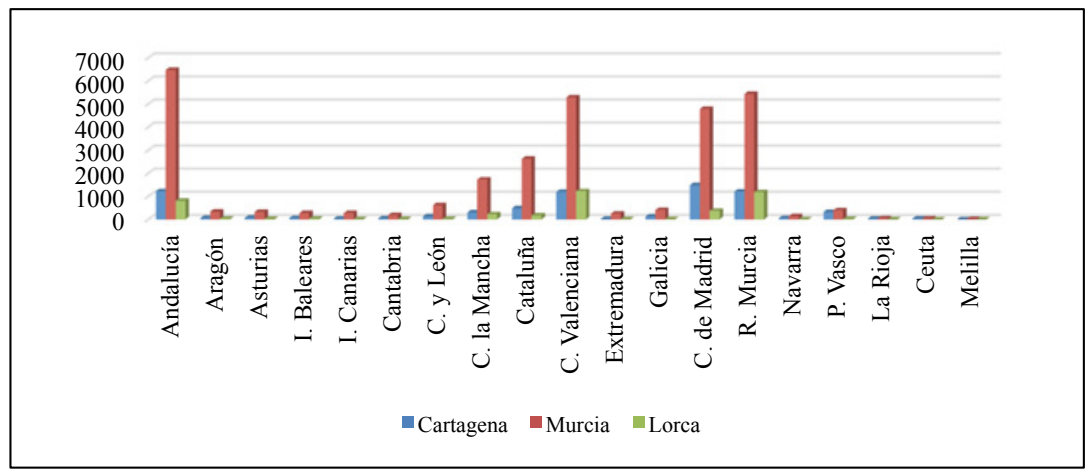

Fuente: Elaboración propia a través de datos de ECONET.

En la figura 7, las ciudades que mayor cantidad de turistas tienen en la Región de Murcia son Cartagena, Murcia y Lorca. Como podemos ver la ciudad que mayor cantidad de turistas recibe es Murcia, pero se ha de mencionar que en los últimos años la ciudad de Cartagena está aumentando la cantidad de turistas que recibe. Centrándonos en la ciudad de Cartagena, se puede ver como la mayor cantidad de turistas que vienen a Cartagena pertenecen a la Comunidad de Madrid, con alrededor de unos 1007 turistas, seguidos de la Comunidad Valenciana y Andalucía, con alrededor de unos 1.000 turistas. En cuanto a los turistas procedentes de la Región de Murcia, se sitúan también alrededor de los 1000. Se encuentran seguido de C. y León y el P. vasco con alrededor de 500 turistas. Mientras que el turismo de las diferentes comunidades se sitúa en alrededor de unos 20 a 50 turistas. 


\section{Figura 8 \\ EVOLUCIÓN DEL NÚMERO DE VIAJEROS POR COMUNIDADES A LO LARGO DE LOS AÑOS}

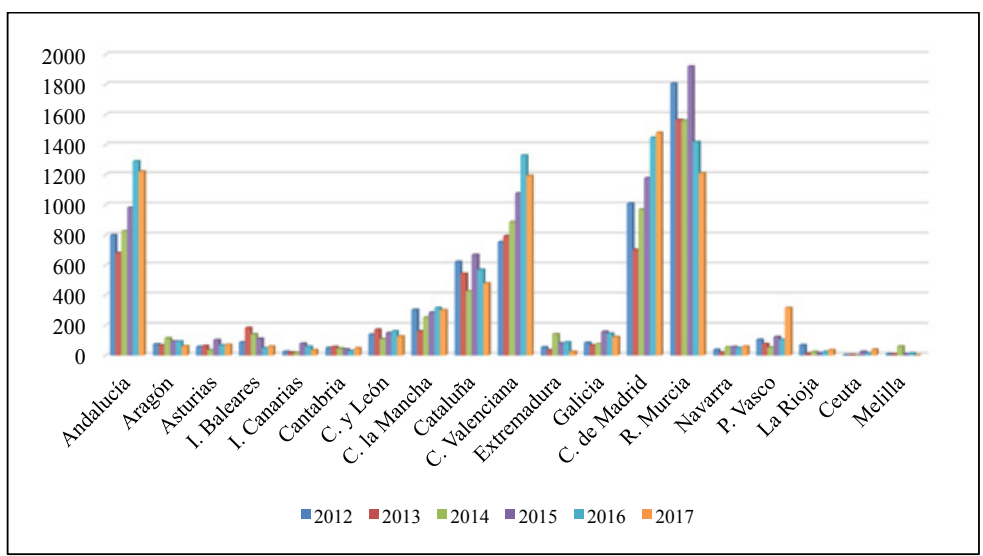

Fuente: Elaboración propia a través de datos de ECONET.

En cuanto a la figura 8 nos centramos únicamente en la ciudad de Cartagena. La comunidad que muestra una mayor dinámica de crecimiento del turismo, son la comunidad valenciana que pasa de aportar 700 turistas a 1.400 turistas, la comunidad de Madrid pasan de aportar 1200 turistas a aportar 1400 turistas, la comunidad andaluza pasa de aportar 800 turistas a los 1200 turistas y la comunidad de Castilla la Mancha pasa de aportar 200 turistas a 400 turistas, mientras que las demás comunidades mantienen un bajo nivel de turistas.

\section{Figura 9 \\ EVOLUCIÓN DEL NÚMERO DE PERNOCTACIONES DE VIAJEROS PROCEDENCIA}

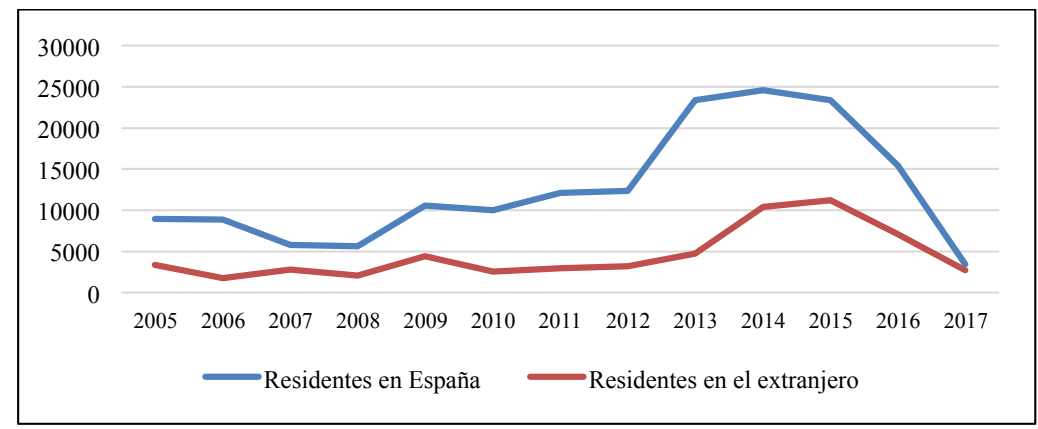

Fuente: Elaboración propia a través de datos de ECONET

En la figura 9, podemos ver que existe una relación entre el número de pernoctaciones y el grado de evolución de la llegada de turistas. En cuanto al número de pernoctaciones de los via- 
jeros residentes en España, se aprecia una tendencia al aumento, pasando de las 9000 pernoctaciones a las 25000 en su momento álgido. Existe un pequeño detrimento de las misas durante las épocas de crisis entre los años 2007 y 2008, en los que pasa de 9000 pernoctaciones a las 5000 pernoctaciones, mientras que a partir de 2012 se produce un exponencial aumento del número de pernoctaciones, pasando de las 12000 pernoctaciones a las 25000 pernoctaciones. Por otro lado, en cuanto a las pernoctaciones de turistas extranjeros, se produce un incremento paulatino desde 2005 hasta 2013, pasando de las 4000 pernoctaciones hasta las 5000 pernoctaciones. En 2013 se produce un importante aumento llegando hasta las 10000 pernoctaciones.

\subsection{La llegada del turismo de cruceros}

El turismo de cruceros es algo muy reciente, puede entenderse como un tipo de resort en constante movimiento que va realizando escalas por los destinos que se encuentran en su ruta. El crucero por el Mediterráneo es una tipología de cruceros de las que más ha crecido y se ha consolidado en los últimos años, concentrando el $30 \%$ del turismo de cruceros mundial, por lo que la ciudad de Cartagena está intentado atraer a los mismo en pos de un beneficio turístico (Tmajon y Valiente, 2012). Cartagena debe ampliar su hinterland, a través de la mejora de los servicios y los recursos de la ciudad, atrayendo así turistas de zonas más lejanas que vengan debido a las buenas experiencias y actividades que ofrezca la ciudad; por lo que los puertos y el paisaje de la ciudad deben aumentar su atractivo (Esteve, García y Gutiérrez, 2014).

A partir de los años 80 el turismo de crucero comienza a desarrollar un crecimiento progresivo, llegando a obtener una posición destacada en cuanto a turismo y ocio se refiere. Pero desgraciadamente la estacionalidad también influye en este tipo de turismo, por lo que será en el verano cuando se concentrará la mayor cantidad de cruceros. Tratando de disminuir este efecto se intentan desarrollar estrategias comerciales en periodos de baja actividad tratando de fomentar una oferta de viaje apetecible para todos los bolsillos (Buades, 2015). La terminal de cruceros del puerto de Cartagena se encuentra situada en la parte exterior del Puerto Deportivo y cuenta con gran cantidad de aparcamientos para autobuses, paradas de taxis, puntos de información y servicios que puedan necesitar los turistas. Además, esta zona está sufriendo una importante transformación durante los últimos años para convertirse en un espacio comercial y cultural apetecible para las personas que visitan la ciudad.

\section{Figura 10 \\ EVOLUCIÓN DEL NÚMERO DE PASAJEROS EN TRÁNSITO}

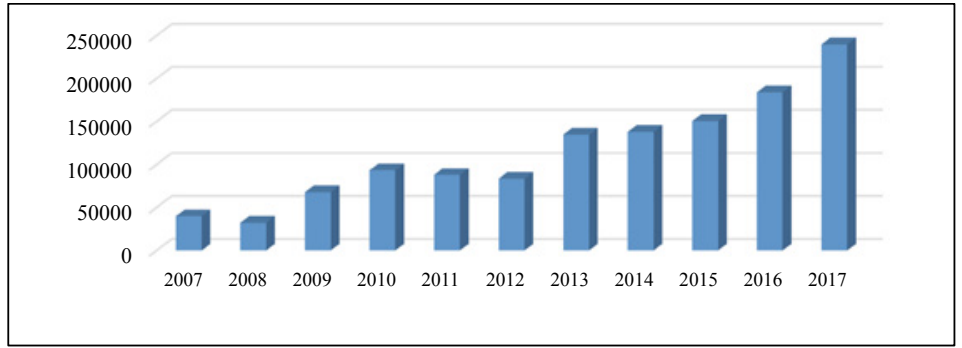

Fuente: Elaboración propia a través de datos del Puerto de Cartagena. 
En la figura 10, se puede observar como desde 2007 hasta 2017 se ha producido un importante incremento del número de cruceristas en Cartagena. En 2007 se contaba con un total de menos de 50.000 cruceristas, pero hasta llegar a 2017 ha sufrido un incremento de 200.000 cruceristas, hecho muy importante para la ciudad de Cartagena, ya que está volcando todo su interés en la atracción de cruceros para su desarrollo turístico. Ayudándonos de la figura 11 se puede atestiguar que no es debido a la existencia de un crecimiento exponencial del número de cruces, sino más bien de un aumento de plazas de los mismos, ya que los busques que últimamente están llegando a la ciudad poseen una capacidad mayor.

\section{Figura 11 \\ EVOLUCIÓN DEL NÚMERO BUQUES}

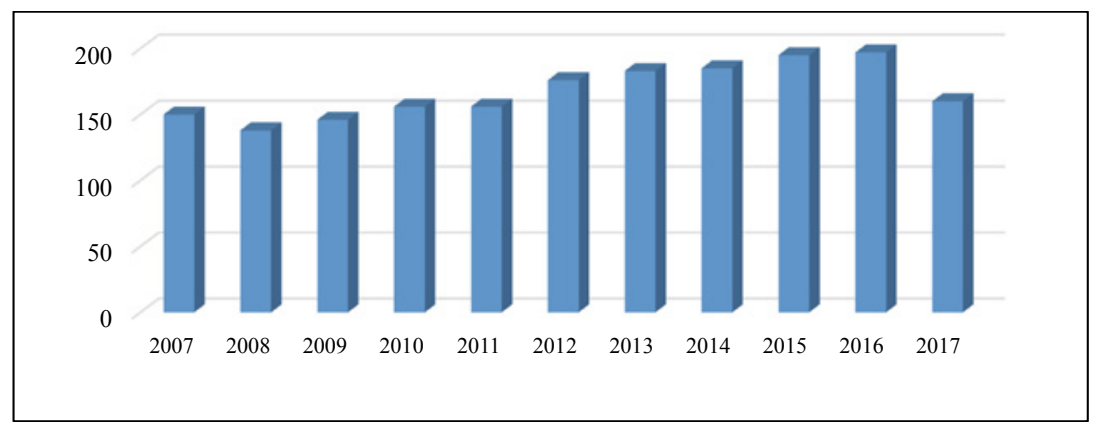

Fuente: Elaboración propia a través de datos del Puerto de Cartagena

En resumen, en los últimos años Cartagena se está convirtiendo en un importante destino turístico de cruceros, ya que las escalas de estos son cada vez más frecuentes y de mayor envergadura. Algunas de las empresas más importantes y de mayor envergadura, cuyos buques atracan en el puerto de Cartagena son MSC cruceros, Magnifica, Royal Princess y Norwegian Spirit entre muchas otras. Dentro del turismo de cruceros, es importante también destacar el consorcio "Amigos de los Cruceros", que está creado por gran cantidad de centros de restauración y ocio, en colaboración con el Ayuntamiento de Cartagena y la Cámara de Comercio de Cartagena, en busca del aprovechamiento económico del turismo de cruceros. Cuando un crucero de más de 300 pasajeros atraca en el puerto los distintos componentes de esta asociación abren sus comercios en busca de rentabilidad económica.

\subsection{Itinerarios culturales}

Debido a la diversidad de elementos patrimoniales existentes es necesaria la realización de itinerarios por época a la hora de visitar la ciudad. Realizar un itinerario implicaría transportarse a través de cada lugar que manifieste una parte de esta historia. En el siguiente mapa se pueden ver los diversos itinerarios por época que atraviesan la ciudad. 
Figura 12

ITINERARIOS DE LA CIUDAD DE CARTAGENA

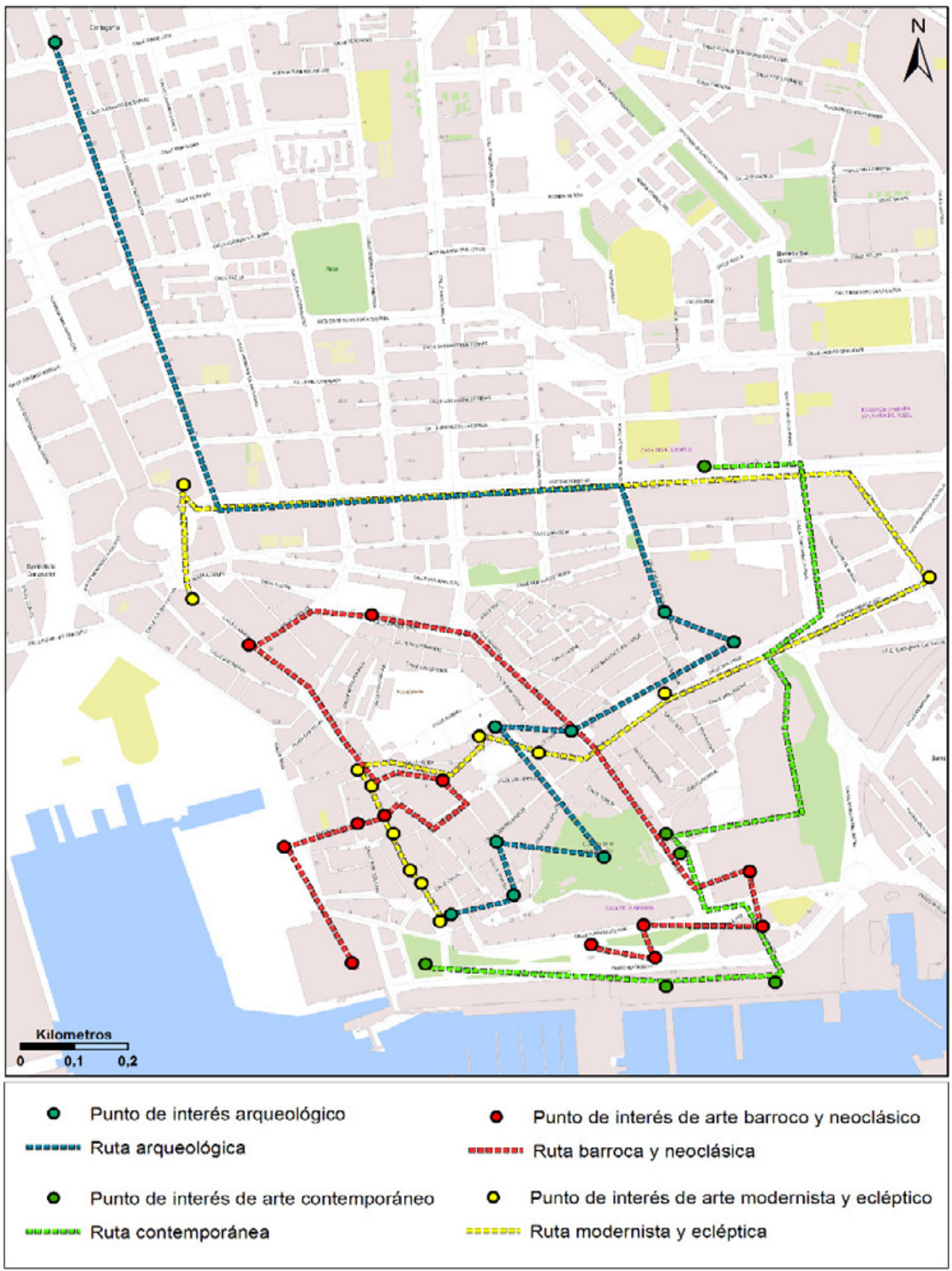

Fuente: Elaboración propia. 


\section{UNA OFERTA VARIADA DE RECURSOS TURÍSTICOS}

El descubrimiento del patrimonio oculto de Cartagena así como el desarrollo del turismo ha llevado a la creación de grandes espacios monumentales en la ciudad, mejorando de esta manera el aprovechamiento turísticos que se le puede dar, y llenando la ciudad de nuevos edificios contemporáneos.(Ayuntamiento de Cartagena, 2005).

\subsection{La oferta museística}

- Museo Nacional de Arqueología Subacuática (ARQVA) es la institución responsable de conservar el patrimonio subacuático español para uso y disfrute de los visitantes. Sus principales objetivos son el estudio, conservación y difusión de los restos hallados en la excavación de yacimientos subacuáticos, en cooperación con los demás estados participantes en el Convenio de la UNESCO. El museo posee una amplia colección de época fenicia debido a los pecios encontrados en mazarrón, y posee además el cargamento que transportaba la fragata Nuestra señora de las Mercedes. Además forma parte de la red de museos del Ministerio de Educación, Cultura y Deportes a través del catálogo on-line CERES. .

- Museo Arqueológico Municipal: Fundado en 1943 tuvo diferentes emplazamientos hasta que en 1982 se inauguró la actual sede emplazada sobre la necrópolis tardorromana excavada años atrás. Esta estructura le confiere una gran cantidad de epigrafía funeraria, aunque entre su colección tampoco debemos olvidar las secciones de minería romana, herramientas, utensilios de la época o producciones cerámicas. Además cuenta con la Asociación de Amigos del Museo Arqueológico de Cartagena (MVSAEDOMUS) que vela por la cultura e historia de la ciudad.

- Museo del Teatro Romano de Cartagena: La recuperación del Teatro Romano de Cartagena así como la gran cantidad de piezas encontradas hicieron necesario la creación de un espacio musealizado. La perfecta concepción del museo permite su entrada por el Palacio Pascual de Riquelme y la llegada al teatro como culmen del recorrido tras pasar por debajo de la Iglesia de Santa María la Vieja.

- Museo Histórico Militar de Cartagena: Se ubica en el histórico edificio del Real Parque y Maestranza de Artillería, siendo inaugurado en 1997. Este edificio pertenecía al conjunto de instalaciones militares que se crearon en Cartagena en el s. XVII. En su interior se recogen aspectos relacionados con la historia militar de la ciudad, así como la evolución de sus armas, uniformes y pinturas.

- Museo Regional de Arte Moderno (MURAM): Su principal objetivo es mostrar y difundir las manifestaciones artísticas desde finales del s. XIX. En su interior se pueden encontrar obras de artistas como Rodin, Dalí, Tapies, Chillida, etc. Ubicado en el Palacio Aguirre y su edificio anexo - de construcción contemporánea

- Museo Carmen Conde-Antonio Oliver: Este museo pretende dar a conocer el legado del matrimonio de escritores. Se encuentra situado en el Centro Cultural "Ramón Alonso Luzzy" en el cual se reconstruyó el ambiente en el que el matrimonio desarrollaba sus obras cedidas al ayuntamiento de Cartagena, así como mobiliarios y objetos de decoración de su casa. 
- Refugio-Museo de la Guerra Civil: El museo se encuentra situado en las galerías del interior del cerro de la Concepción, que constituían una red de refugios antiaéreos. En este espacio se pueden encontrar diversos utensilios que se encontraban dentro de esta red de galerías.

\subsection{Restauración}

El centro de Cartagena comienza a desarrollarse en los últimos años debido a los proyectos de renovación y rehabilitación de los edificios existentes, y aprovechando la llegada de turismo a la ciudad. Cartagena posee una gran oferta gastronómica muy diversificada, pasando de restaurantes de alta cocina, a establecimiento de tapas o comida rápida. Por norma general, la actividad gastronómica se concentra en la Calle Mayor y la Calle Murcia, pero se percibe una clara tendencia a la expansión condicionada por la remodelación de más áreas de la ciudad.

\section{Figura 13
CAFETERÍAS Y RESTAURANTES DE LA CIUDAD DE CARTAGENA}

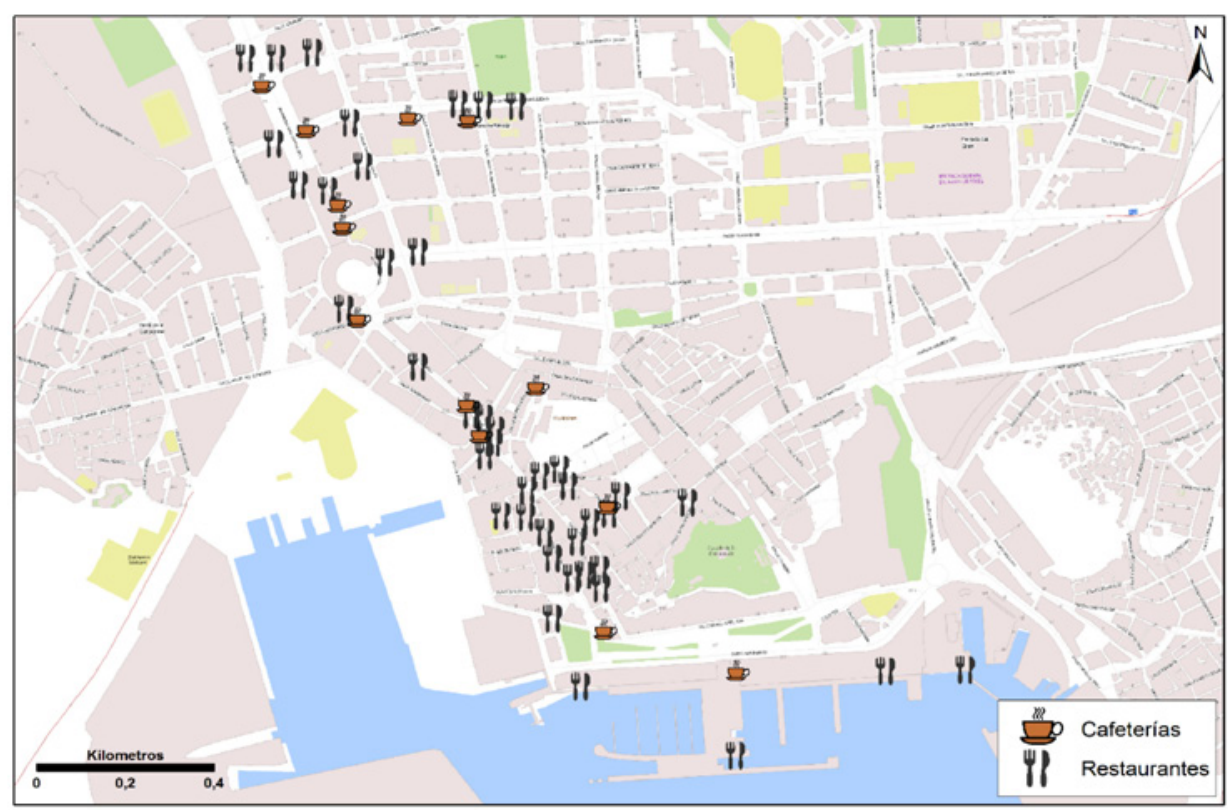

Fuente: Elaboración propia.

En la figura 14, podemos apreciar las diferencias existentes entre las distintas tipología de restaurantes, así como el n'mero de plazas que concentra cada uno de ellos. En el primer gráfico podemos ver la evolución que ha tenido los distintos tipos de restaurantes 
en la ciudad de Cartagena. Tal y como podemos ver, la tipología de restaurantes que más destaca es la de restaurantes de tercera y cuarta categoria, se puede ver cómo ha existido un detrimento progresivo de los restaurantes de tercera categoría, mientras que por el contrario los restaurantes de cuarta categoría han evolucionado progresivamente. Se pasa en 2002, en los restaurantes de tercera categoría, de un total de 70 restaurantes a 101 en 2013, cosa que continuará evolucionando hasta el día de hoy. Mientras que en cuanto a los restaurantes de tercera categroría, en 2002 podemos ver un total de 172 plazas que evolucionan hasta las 289 plazas en 2013. En cuanto a cantidad de plazas en restaurante, como se puede apreciar, más del $60 \%$ del las plazas le corresponde a los restaurantes de cuarta categoría, y más del $30 \%$ corresponde a los restaurantes de tercera categoría. Como podemos ver los restaurantes de tercera categoría vemos en 2002 un total de 8409 plazas hasta las 10301 plazas en 2013; por otro lado, en los restaurantes de cuarta categoría pasamos de 14.152 plazas en 2002 a las 18897 plazas en 2013.

Figura 14

\section{EVOLUCIÓN DE LA TIPOLOGÍA DE RESTAURANTES}

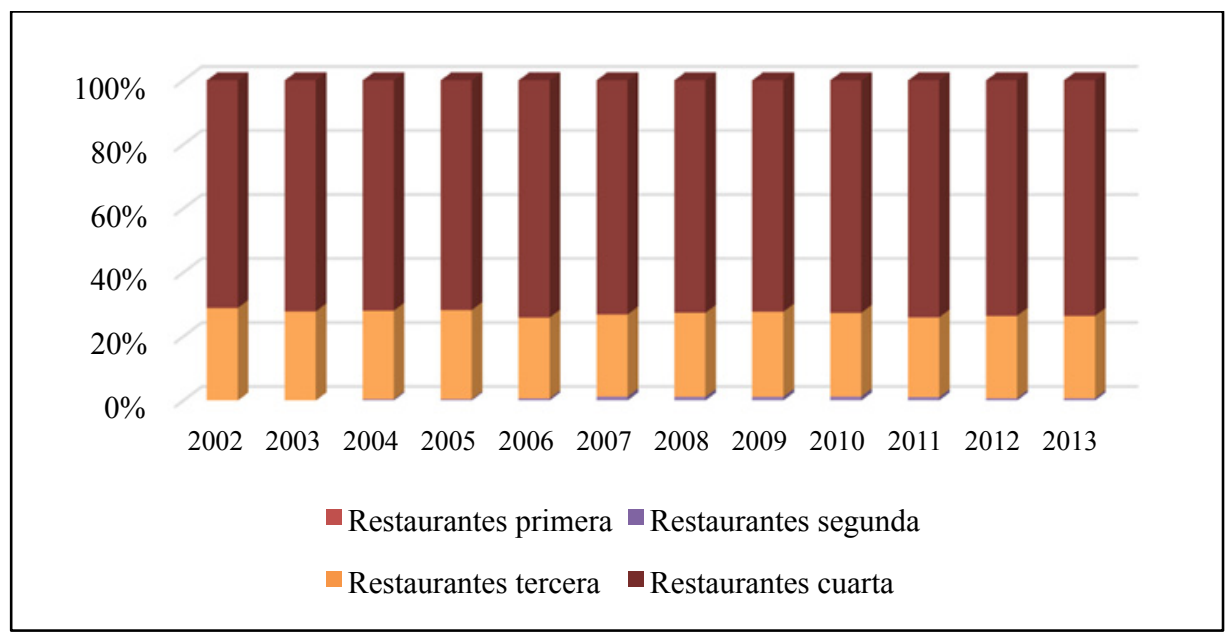

Fuente: Elaboración propia a través de datos del Ayuntamiento de Cartagena.

Restaurantes de primera categoría (cuatro tenedores): Cumple una serie de requisitos como entrada independiente, guardarropas, calefacción, refrigeración, instalaciones de primera calidad, etc.

Restaurantes de segunda categoría (tres tenedores): no se utilizará al mismo tiempo el acceso para los proveedores de mercancías, comedor con superficie adecuada a su capacidad, servicios sanitarios independientes, instalaciones de primera calidad.

Restaurantes de tercera categoría (dos tenedores): Materiales en buen estado de conservación, comedor con suficiente capacidad, el personal deberá estar identificado como mínimo con una chaqueta. 
Restaurantes de cuarta categoría (un tenedor): deberá tener comedor independiente de la cocina y materiales en buen estado de conservación y con el personal perfectamente aseado.

Figura 15

EVOLUCIÓN DE LA TIPOLOGÍA DE CAFETERÍAS

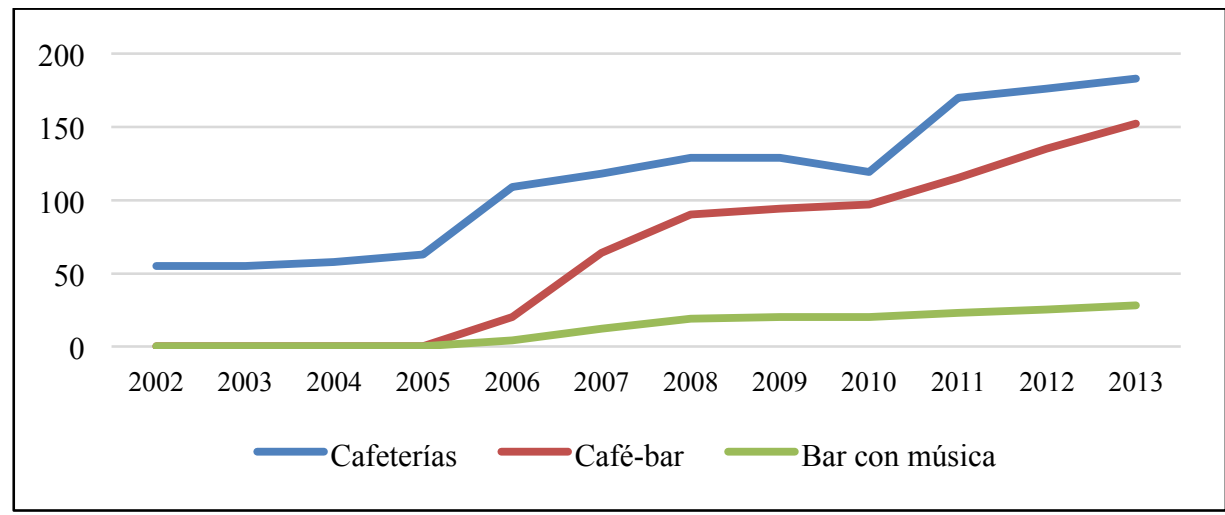

Fuente: Elaboración propia a través de datos del Ayuntamiento de Cartagena.

Tal y como vemos en la figura 15, podemos ver cómo entre 2002 y 2005 no existían ni café-bar ni bares con música, por lo tanto, únicamente existían cafeterías que comienza a aumentar paulatinamente, pasando de 55 cafeterías a 63 en 2006. A partir de 2007 podemos ver cómo comienza un crecimiento imparable de este tipo de establecimientos. En cuanto a las cafeterías, a partir de 2005 sufre un crecimiento imparable, pasando en 2005 de tener 60 cafeterías a 183 en 2013 cosa que irá aumentando progresivamente. Podemos ver cómo en 2010 llega un punto de inflexión debido a que son los años más acusados de la crisis y se produce un pequeño descenso. En cuanto a los café-bar a partir de 2005 comienzan a surgir con un ritmo exponencial de crecimiento pasando de tener ninguna a tener 152 café-bar. En cuanto a los bares con música, comienzan a surgir pero con un ritmo más cometido, pasando de tener 0 en 2005 a poseer unas 28 en 2013 a pesar de su lento pero progresivo aumento, destinadas sobre todo al ocio nocturno.

\subsection{Agencias de viaje}

En cuanto a las agencias de viaje, nos damos cuenta de que son un elemento determinante para la distribución de servicios turísticos ya que ejercen de nexo entre los clientes y el producto ofertado. Estos intermediarios permiten servicios de asesoramientos y distribución del turismo. Pero en los últimos años estas están quedando obsoletas debido a la existencia de gran cantidad de páginas de internet existentes para obtener las mejores ofertas de vuelo y pernoctaciones. (Bigné, Font y Andreu, 2000). 


\section{Figura 16 \\ EVOLUCIÓN DE LA CANTIDAD DE AGENCIAS DE VIAJE}

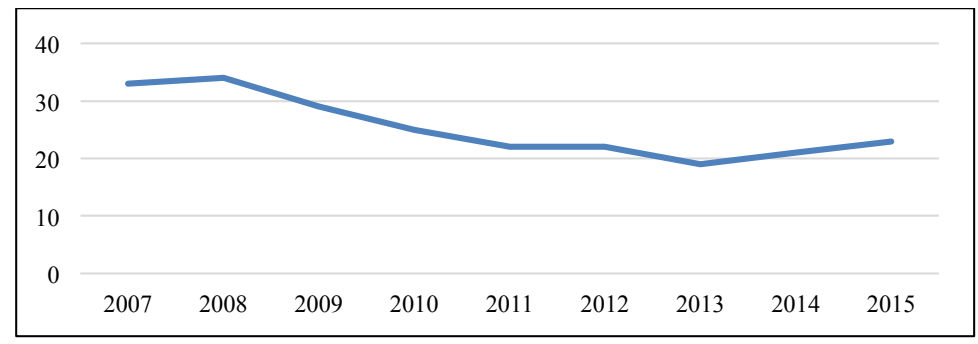

Fuente: Elaboración propia a través de datos del Ayuntamiento de Cartagena.

En relación a la figura 16, se puede ver como la tendencia de la cantidad de agencias de viaje ha ido descendiendo progresivamente; esto es debido, como se ha comentado anteriormente, al aumento de páginas web donde contratar servicios, por lo que las agencias de viaje siguen una tendencia regresiva que supondría el cierre de diversas oficinas instaladas en la ciudad.

\subsection{Oferta de transporte turístico}

Los servicios de transporte son muy importantes para las ciudades. En Cartagena se pueden distinguir dos tipos de transportes: específicos para turistas en la ciudad, y los demás servicios de transporte. En todos estos transportes existen deducciones económicas para estudiantes, desempleados, jubilados, discapacitados, familias, etc.

- Bus turístico: Costa de un autobús de dos plantas equipado con audio guías en diversos idiomas a partir de la cual podemos ver la Cartagena antigua, así como sus murallas, edificios y restos arqueológicos. El trayecto dura de 45 minutos.

- Barco turístico: le ofrece una visión diferente a la ciudad de Cartagena, y pudiendo observar la dársena natural de la ciudad, conocer la defensa de la ciudad, monumentos de diferentes épocas, etc. Dando un paseo para poder disfrutar de todo el entorno portuario, un pase turístico apto para todas las edades.

\section{PERCEPCIÓN TURÍSTICA Y DE SERVICIOS}

\subsection{Análisis de la percepción por parte de turistas y residentes}

En cuanto a las encuestas, al igual que en el trabajo de Mulero (2016) se se abordará en primer lugar conocer el proceso de elección de este destino, a continuación la encuesta en sí se ha dividido en dos partes, la primera hace referencia a la satisfacción de los encuestados en relación a su percepción de la ciudad; por otro lado, en la segunda parte se pretende atestiguar el grado de conocimiento acerca del patrimonio cultural de la ciudad para atestiguar la importancia de los diferentes edificios en relación a las personas encuestadas. No debemos olvidar que se trata de una percepción social, por lo tanto, esta 
variará en función de la sociedad y del tiempo transcurrido, por lo que no se puede tomar como una ciencia absoluta.

1. ¿Es la primera vez que visita Cartagena?

\section{Figura 17 \\ TIPO DE VIAJE EN \%}

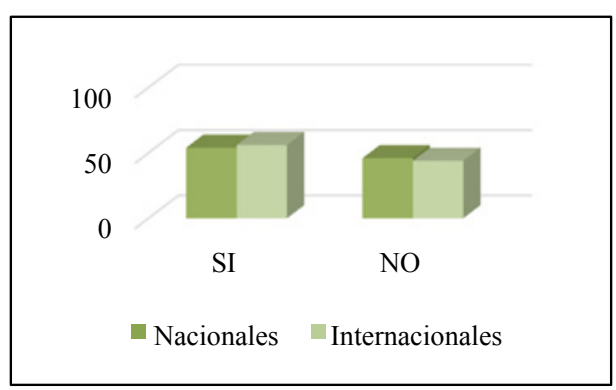

Fuente: Elaboración propia.

En la figura 17 se puede ver el porcentaje de turistas nacionales e internacionales que visitan Cartagena por primera vez. Esta cifra se encuentra bastante similar, ya que el $54^{`} 3 \%$ de turistas nacionales visitan Cartagena por primera vez en referencia a los $55^{\prime} 7 \%$ de turistas internacionales que es la primera vez que visitan Cartagena; por lo tanto, esto nos refleja un punto positivo debido a que se muestra como un lugar atractivo para poder atraer a nuevos turistas, aunque se puede apreciar además una consolidación debido a que el $45^{\prime} 7 \%$ de turistas nacionales y el $44^{\prime} 3 \%$ de turistas internacionales ya la habían visitado.

2. ¿Ha venido usted sólo o con otras personas (Solo, amigos, pareja, familia, grupo organizado)?.

Figura 18

\section{TIPO DE VIAJE EN \%}

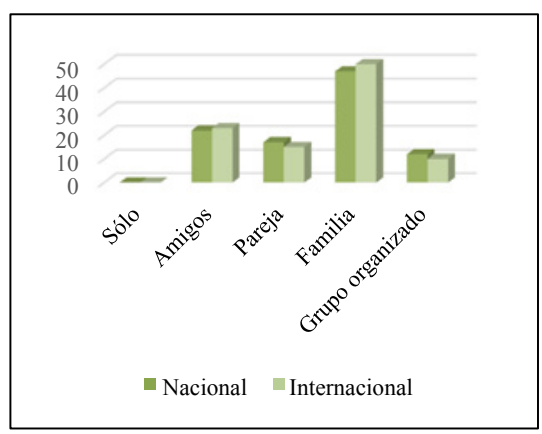

Fuente: Elaboración propia. 
En cuanto al tipo de viaje que se realiza por parte de los turistas, tanto de los nacionales $\left(47^{\prime} 8 \%\right)$ como los internacionales $\left(50^{\prime} 8 \%\right)$, se puede apreciar cómo en su mayoría es un viaje familiar debido a que los servicios existentes en la ciudad facilitan de forma muy clara este tipo de viajes. Destacan también los viajes en pareja, contando con un 17`3\% de turistas nacionales y un $15^{\prime} 4 \%$ de los turistas internacionales; seguido de los viajes con amigos, $22^{\prime} 4 \%$ turistas nacionales y $23^{\prime} 1 \%$ turistas internacionales. Actualmente algunas tour operadoras realizan viajes organizados sobre todo para personas de la tercera edad, por lo que encontramos que el $12 \%$ de los turistas nacionales vienen en viajes organizados, al igual que el 106\% de los turistas internacionales.

3. Durante su estancia se hospedará en (Hotel, hostal, pensión, casa de familiares/ amigos, no se hospedará):

Figura 19

\section{TIPO DE HOSPEDAJE EN \%}

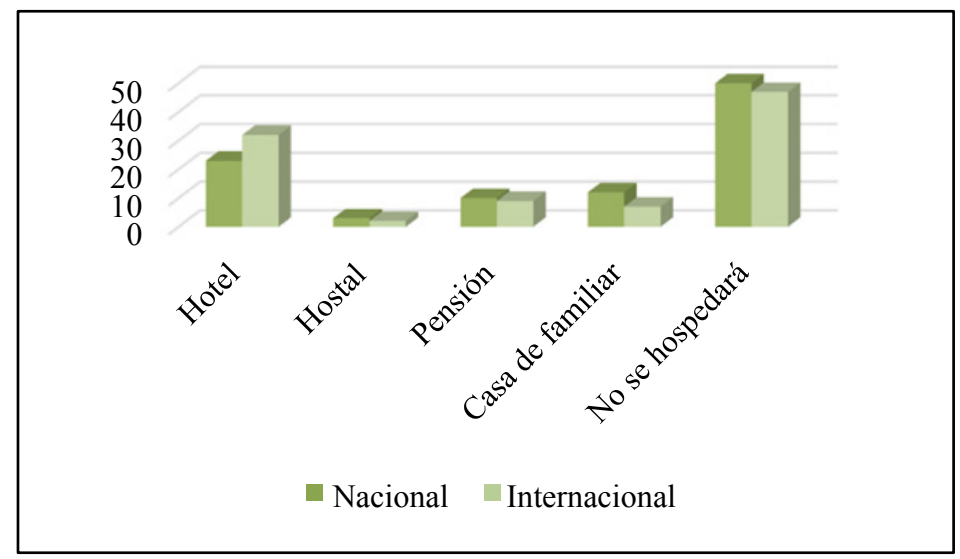

Fuente: Elaboración propia.

Durante la estancia los turistas pudieron hospedarse en diversos lugares. El 50^1\% de los turistas nacionales y el $47^{\prime} 9 \%$ de los turistas internacionales no se hospedará lo que nos indica que Cartagena debe seguir trabajando para convertirse en un lugar con la suficiente cantidad de recursos como para pernoctar. Es también destacable el hospedaje en el hotel por parte de turistas nacionales (23’7\%) e internacionales (32’5\%). Es destacable también la pernoctación en las pensiones (10`3\% de los turistas nacionales y $9^{`} 7 \%$ de los turistas internacionales), así como que los turistas pasen la noche en casa de amigos o familiares (12'5\% turistas nacionales y $7^{\prime} 8 \%$ turistas internacionales), quedando de manera muy residual la pernoctación en los hostales (3`4\% turistas nacionales y $2^{\prime} 1 \%$ turistas internacionales).

4. A la hora de buscar información ¿Qué medios utilizó (Agencias de viaje, Internet, guías turísticas, amigos/familia)? 


\section{Figura 20 \\ BÚSQUEDA DE INFORMACIÓN EN \%}

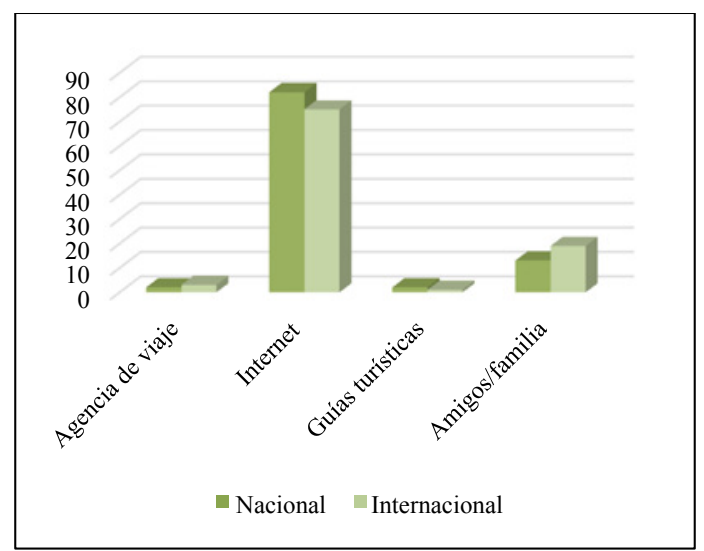

Fuente: Elaboración propia.

A la hora de buscar información sobre el destino turístico, la mayoría de turistas tanto nacionales $\left(82^{\prime} 4 \%\right)$ como internacionales $\left(75^{\prime} 7 \%\right)$ consultó información a través de Internet, o pidió información a familiares o amigos (13’2\% turistas nacionales y 19`7\%turistas internacionales). Mientras que tanto las agencias de viajes $\left(5^{\prime} 7 \%\right.$ de losturistas) y las guías turísticas (3’3\%) han perdido una gran importancia.

5. ¿Qué le llevó a elegir Cartagena?

\section{Figura 21 \\ MOTIVO DE LA ELECCIÓN DE CARTAGENA COMO DESTINO EN \%}

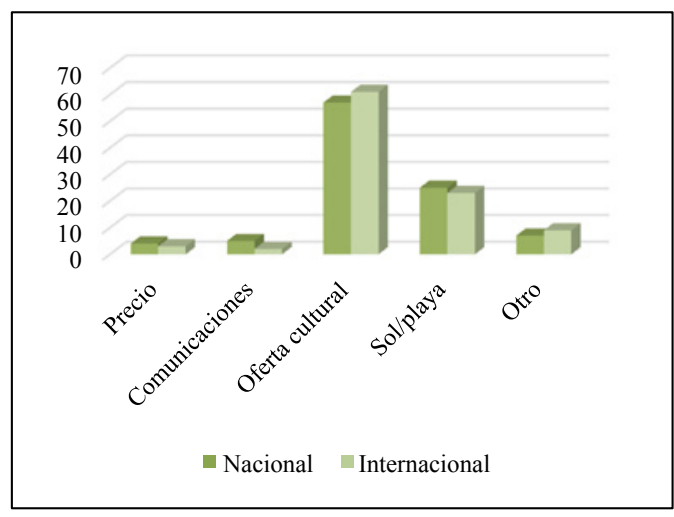

Fuente: Elaboración propia. 
En cuanto a los motivos que les llevó a los turistas a elegir Cartagena como destino destaca la oferta cultural correspondiendo al 57’4\% de los turistas nacionales y al 612\% de los turistas internacionales. Por otro lado, es también destacable la importancia que ha tenido su posición geográfica en cuanto a la relación con el turismo de sol y playa, contando con un $25^{\prime} 1 \%$ de turistas nacionales y un $23^{\prime} 7 \%$ de turistas internacionales. Además es importante las vías de comunicación existentes con la ciudad; teniendo una importancia mayor para los turistas nacionales $(5,4 \%)$ que para los turistas internacionales (2`1\%), ya que los primeros suelen venir a la ciudad en coche, mientras que los segundos lo hace a partir del avión o en crucero. Con menos importancia es también destacable el precio de los servicios, motivando la llegada del 4`2\% de turistas nacionales y del 3’5\% de turistas internacionales.

Figura 22

\section{ENCUESTA DE SATISFACCIÓN}

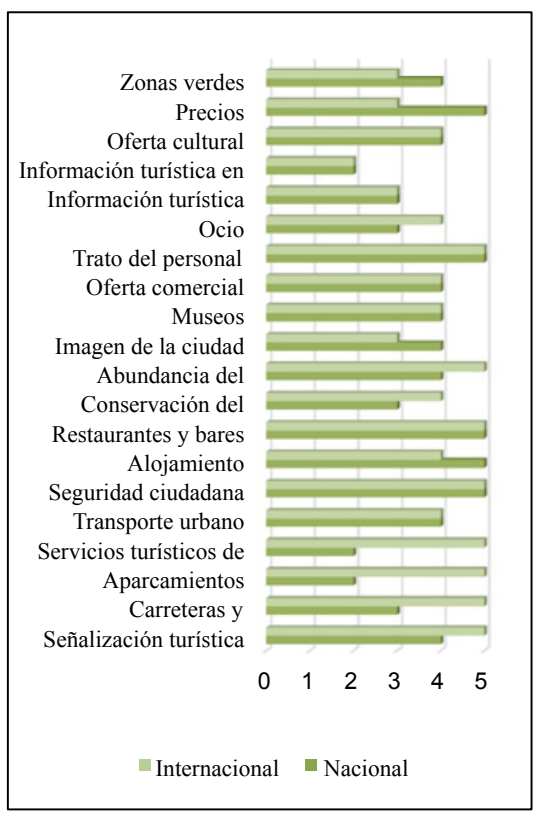

Fuente: Elaboración propia.
Figura 23

\section{IMPACTO DEL TURISMO}

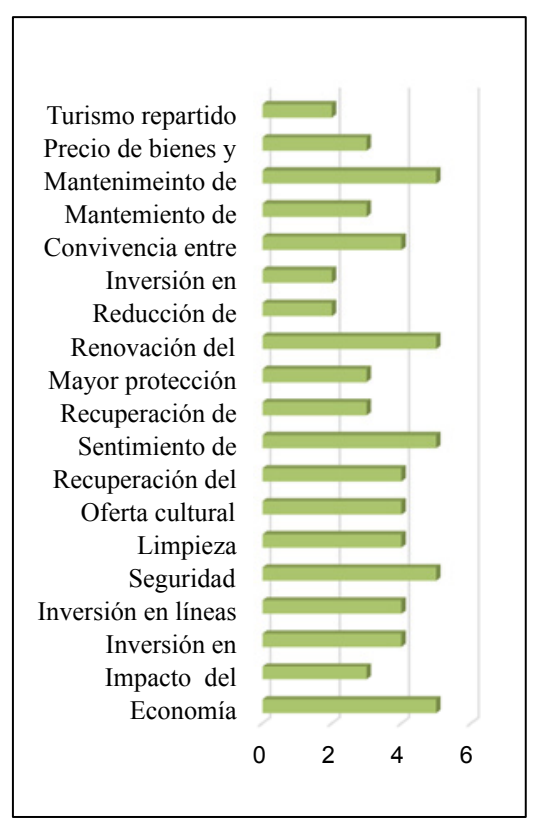

Fuente: Elaboración propia.

En la figura 22 se puede ver el grado de satisfacción de los turistas nacionales e internacionales respecto a diversas preguntas sobre la ciudad. En cuanto a la señalización turística, los turistas nacionales $\left(4^{\prime} 1\right)$ e internacionales $\left(4^{\prime} 7\right)$ opinan que es buena, así como la seguridad ciudadana, los bares y restaurantes, y el trato personal (5 puntos ambos tipos de turistas), el alojamiento (4`9 turistas nacionales y $4^{\prime} 6$ turistas internacionales), la abundancia del patrimonio, así como los precios. Con respecto a otros aspectos la puntuación de la ciudad sufre un leve descenso; entre estos podemos encontrar, las carreteras y comunicaciones para llegar a la ciudad (3`2 turistas nacionales y $4^{\prime} 8$ turistas 
internacionales), la cantidad de aparcamientos (2’5 turistas nacionales y 5 turistas internacionales), los servicios turísticos de transporte urbano (2 turistas nacionales y $4^{\prime} 6$ turistas internacionales), trasporte urbano, la conservación del patrimonio, la imagen de la ciudad (4’2 turistas nacionales y 3’4 turistas internacionales), los museos la oferta comercial, la oferta de ocio, el grado de información turística en la ciudad (3’6 turistas nacionales y 3’4 turistas internacionales), o el grado de información turística en su lugar de origen (2`1 turistas nacionales y 2’5 turistas internacionales), así como las zonas verdes (4’3 turistas nacionales y 3’2 turistas internacionales).

Realizando un resumen de lo anteriormente mencionado, los precios, se ha de recordar que se puntúan siendo 1 caros y 5 baratos; estos se encuentran dentro de la media del resto de ciudades turísticas, incluso en algunos establecimientos más baratos en función de la cercanía o lejanía a la calle mayor; aunque en cuanto al ocio nocturno la puntuación baja debido al escaso número de lugares. Por otro lado, es importante también hacer mención a que la mayoría de turistas calificaron a los residentes como muy hospitalarios, considerándose dentro de esto el trato durante la visita en los diferentes lugares y establecimientos. En cuanto a la información turística de Cartagena en sus lugares de origen esta es reducida debido a que todavía no ha adquirido una gran trascendencia internacional, aunque este hecho se ve paliado por la gran cantidad de recursos informativos dentro de la ciudad. Por otro lado, se obtiene la puntuación acerca de la oferta comercial del lugar que presenta una puntuación buena o muy buena debido a la iniciativa del Centro Comercial Abierto del Casco Antiguo. Si se presta atención a la opinión acerca de los museos y el grado de conservación se puede apreciar que esta es buena, y que gracias a los proyectos del Ayuntamiento de Cartagena irá mejorando. Por último, las zonas verdes se valoran dentro de los aspectos normales debidos en gran parte a no ser demasiado vistosas en comparativa con las zonas verdes del norte de Europa debido sobre todo al clima en el que se encuentran, y además estas son escasas en el Casco Antiguo.

En la figura 23 se puede apreciar la percepción acerca del impacto que el turismo ha tenido en la ciudad por parte de los residentes. En este gráfico se puede ver cómo los encuestados opinan que el turismo y el patrimonio han tenido un fuerte impacto en la economía de la ciudad, aunque no en sí en su propia familia, puntuando este ámbito con un 3’2. Destacan también que ha ejercido una fuerte influencia en la inversión en transporte (3’7) así como en sus líneas y horarios (4`2), a pesar de que en sí no se ha producido una importante inversión en infraestructura (2`4); opinando también que se ha producido un aumento de la seguridad (5) debido a esto, así como de la limpieza de la ciudad (3’6). Gracias a la importancia del turismo se ha procedido a la realización de diversos planes de renovación que opinan han provocado un aumento de la oferta cultural (3’8), así como de la recuperación del patrimonio (4’3) por lo que los cartagineses han adoptado un sentimiento de patrimonio único (5); aunque a pesar de esto no existe una cierta impresión de que se hayan recuperado zonas degradadas (3'2), ni se han reducido las diferencias económicas interbarrios (2`1). Si se han llevado a cabo medidas de protección medioambiental en cierto modo (3’6) que ha llevado a la renovación del paisaje de la ciudad $\left(4^{\prime} 7\right)$, provocado por una pequeña inversión en el mantenimiento de zonas verdes (3'5). A pesar de lo anteriormente mencionado, los residentes opinan que existe una buena convivencia 
entre turistas y residentes $\left(4^{`} 3\right)$ por lo que el turismo no se ha convertido en un problema, y ayudando este al mantenimiento de las tradiciones (48) a pesar de según

\subsection{Análisis de la percepción por parte de expertos y profesionales en turismo, y técnicos de la administración de Cartagena.}

A continuación se va a proceder al análisis de la percepción que poseen los diferentes expertos y profesionales en turismo, y técnicos de la administración de Cartagena, para obtener de esta manera una percepción diferente y más cualificada, que la de los turistas y residentes del entorno de Cartagena. En la siguiente tabla podemos ver la muestra a la cual se ha procedido a pasar las entrevistas.

Tabla 1

MUESTRA SELECCIONADA DE LAS ENTREVISTAS

\begin{tabular}{|l|c|c|}
\hline Colectivo & $\mathbf{N}^{\mathbf{0}}$ cuestionarios & Código \\
\hline Técnicos de Turismo: Ayuntamiento de Cartagena & 2 & TEC -TU \\
\hline Miembros de la Asociación Casco Antiguo de Cartagena & 2 & A-CAC \\
\hline Técnicos de Patrimonio: Ayuntamiento de Cartagena & 2 & TEC-PA \\
\hline Directores de museos de Cartagena & 4 & D-MU \\
\hline $\begin{array}{l}\text { Técnicos de Ordenación Urbana: Ayuntamiento de } \\
\text { Cartagena }\end{array}$ & 2 & TEC-OU \\
\hline Especialistas en paisaje & 4 & E- PAI \\
\hline
\end{tabular}

Fuente: Elaboración propia

En las siguientes preguntas destacaremos las preguntas más importantes y que más se han destacado en las encuestas, agrupándolas en respuestas similares:

1. ¿Consideras el paisaje de Cartagena lo suficientemente representativo para su conocimiento en otros lugares de España o fuera de ella?

\section{Figura 24 \\ REPRESENTATIVIDAD}

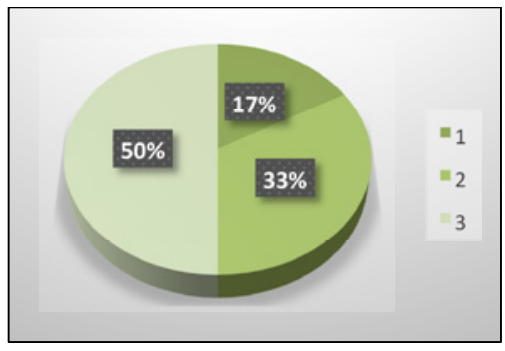

Fuente: Elaboración propia. 
En esta pregunta se trata de averiguar la percepción de la representatividad del paisaje. En estas respuestas destaca una principalmente que es la 3 y que contiene el $50 \%$ de las respuestas y nos dice "No es muy representativo en su conjunto pero sí que tiene algunos aspectos destacables y representativos en sí mismo, como el teatro romano con la Catedral Vieja y la Sierra litoral de fondo". En segundo lugar encontramos la respuesta 2 con el $33 \%$ de las respuestas y nos dice "No es único pero es importante su puesta en valor para desarrollar su potencial de crecimiento pero bien planificado para evitar problemas de excesivo turismo".

Y por último con un $17 \%$ encontramos la respuesta "Es uno de los paisajes más singulares de la comunidad debido a su puerto natural, las transformaciones de su bahía, las colinas y la convivencia de diferentes épocas". En resumen podemos destacar que a pesar de ser representativo de la ciudad no es único aunque si se aprecia un estima muy importante por parte de la ciudad.

2. ¿Consideras que únicamente el patrimonio monumental de Cartagena ha sido objeto de interés turístico?

\section{Figura 25 OBJETO DE INTERÉS}

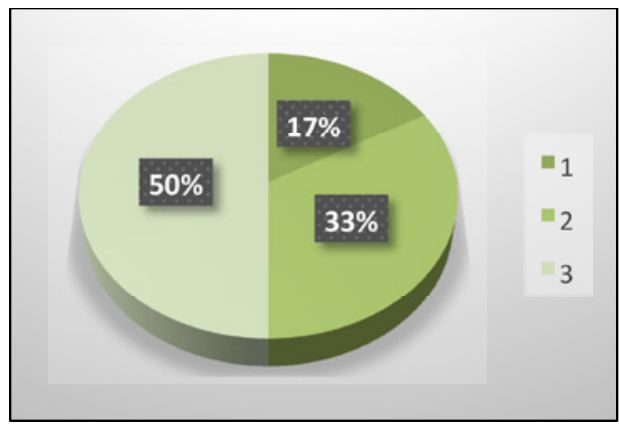

Fuente: Elaboración propia.

En esta pregunta se presta atención al patrimonio monumental, destaca la pregunta número 3 con un $50 \%$ de respuestas que nos dice "A pesar de su importante papel ha sido el turismo de sol y playa lo que ha jugado un papel relevante y ha llevado sus turistas a la visita de la ciudad", la segunda respuesta más importantes encontramos la respuesta 2 con un 33\% de las respuestas que nos dice "En las últimas décadas, el potencial histórico de la ciudad y su puesta en valor a creado la imagen de turismo cultural”, y por último, "El patrimonio ha sido muy importante pero hay que entender que viene acompañado con unos recursos en su conjunto como el paisaje, la gastronomía, los edificios militares, la playa, el puerto y la planificación”; en resumen podemos ver que las respuestas de los expertos nos dicen que el patrimonio a pesar de ser importante no es únicamente lo más importante. 
3. ¿Consideras que los recientes hallazgos arqueológicos pueden suponer el aumento de visitas turísticas o podrían existir otros motivos?

Figura 26

\section{HALLAZGOS ARQUEOLÓGICOS}

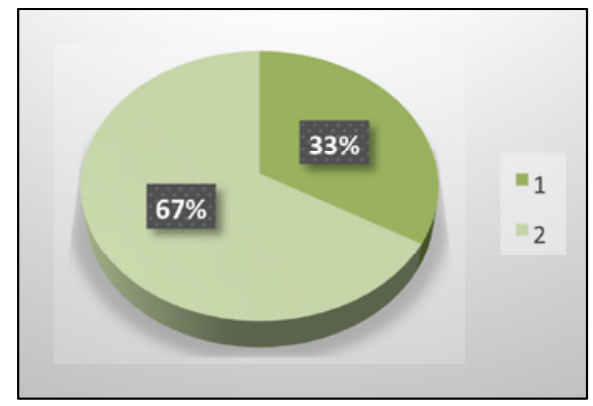

Fuente: Elaboración propia.

En esta pregunta se trata de averiguar si los recientes hallazgos arqueológicos son el principal motivo del aumento de visitas o pudiese haber otro. En esta pregunta, los entrevistados se han dividido en dos respuestas principales. La más importante destaca un $67 \%$ y nos dice El patrimonio arqueológico ha sido el principal aumento de visitas, aunque también se debe prestar atención al urbanístico ya que hay una conexión y no están aislados", y la otra respuesta es "Todo suma, no únicamente los hallazgos arqueológicos sino también los congresos, fiestas, y eventos deportivos”.

4. ¿Qué considera más importante a la hora de atraer turismo: el patrimonio, el paisaje o la ordenación territorial?

Figura 27

ATRACCIÓN DE TURISMO

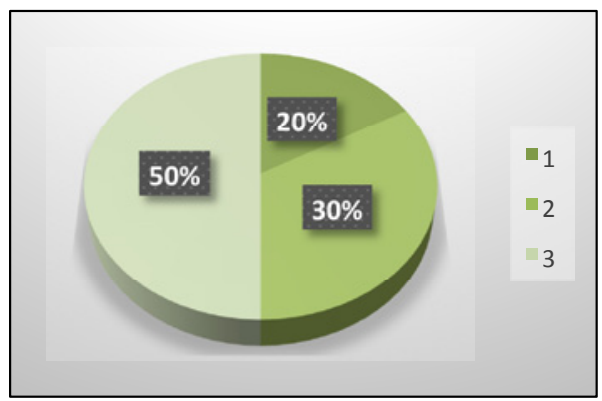

Fuente: Elaboración propia. 
En esta pregunta se trata de averiguar la importancia de los diferentes recursos. En primer lugar destaca la pregunta 3 con un 50\% de las respuestas que nos dice "Lo más importante ha sido el patrimonio ya que los visitantes buscan recursos patrimoniales aunque las tres cosas son importantes", en segundo lugar destaca la pregunta 2 con el $30 \%$ de las respuestas que nos dice "Todo influye, pero sin una buena planificación los elementos patrimoniales no tendrían la infraestructura necesaria”, y por último, destaca la pregunta 1 , con un $20 \%$, que nos dice "El planeamiento es fundamental para valorar las cosas, pero no se puede hablar de él sin tener en cuenta el paisaje cultural y la puesta en valor”. En resumen podemos sacar la idea de que todo en su conjunto es importante para el desarrollo turístico.

Anteriormente se ha estudiado los diferentes recursos que poseía la ciudad de Cartagena para ser un destino turístico con gran potencialidad. A continuación pasaremos a analizar la percepción de turistas y residentes sobre estos aspectos. Para realizar este conocimiento se utilizarán las encuestas de Mulero (2016) ya que abordan de manera muy visual los temas objetos de estudio, a pesar de que se realizarán unas pequeñas modificaciones para adecuarlas mejor a nuestro objeto de interés. A partir de las mismas se conocerá el grado de satisfacción por parte de los turistas, tanto nacionales como internacionales, así como del residente. Las encuestas se realizaron desde al 10 de abril al 12 de mayo, con la intención de obtener una mayor afluencia de público en la ciudad debido a Semana Santa; tomando contacto con los entrevistados in situ en la plaza del Palacio Consistorial. En cuanto al análisis socioeconómico de las personas encuestadas, en la cual podemos ver que destacan los turistas entre 30 y 45 años asalariados, aunque se ha de mencionar que en los últimos años puede existir una variación en la tendencia debido al auge del turismo de cruceros, que traen gran cantidad de personas de la tercera edad.

\subsection{Análisis DAFO}

Existen una serie de riesgos (combinación de fortalezas y amenazas) y los desafíos (combinación de debilidades y oportunidades) que la ciudad de Cartagena debe superar o aprovechar para alcanzar un alto grado de ciudad eminentemente turística, es decir, para definir el rumbo a la hora de desarrollar una estrategia turística (Pardo, Mora y Rojas, 2013). Cartagena se encuentra en un entorno con gran cantidad de potencialidades tanto naturales (bahía portuaria, planitud del terreno, etc.) como culturales (edificios históricos, museos, Cartagineses y Romanos, etc.) que junto con el desarrollo de servicios tratan de atraer a los potenciales visitantes.

Para estudiar los riesgos y los desafíos a los que se enfrenta el entorno urbano de Cartagena se aplicará una metodología DAFO (Espejo, 2008), con el objetivo de estudiar las debilidades y fortalezas con las que cuenta la ciudad; y saber eliminar amenazas y desarrollar oportunidades (González, 2012). Para la realización de este análisis DAFO nos hemos ayudado no solo por las encuestas realizadas a la población, sino también por las realizadas a los diversos técnicos del Ayuntamiento de Cartagena, tabla 1, así como de museos circundantes a las que se han realizado preguntas como ¿Qué mejorarías de tu ciudad? ¿Qué punto fuerte destacarías de la misma? ¿En qué debería basarse el desarrollo local de la ciudad de Cartagena? ¿Qué sucesos o causas pueden provocar el deterioro de la ciudad?, además de las pertinentes en las encuestas. A continuación se pueden ver las debilidades, amenazas, fortalezas y oportunidades que atañen a la ciudad de Cartagena: 
Tabla 2

ANÁLISIS DAFO DE LA CIUDAD DE CARTAGENA

\begin{tabular}{|c|c|}
\hline DEBILIDADES & AMENAZAS \\
\hline $\begin{array}{l}\text { Turismo } \\
\text { - Insuficiencia de líneas de transporte público y } \\
\text { deficiencia de horarios. } \\
\text { - Patrimonio histórico pendiente de } \\
\text { rehabilitación. } \\
\text { - Estacionalidad del turismo y pernoctaciones } \\
\text { mínimas. } \\
\text { - Excesiva madurez de los servicios de } \\
\text { restauración. } \\
\text { - Sector servicios poco profesionalizado y } \\
\text { obsoleto. } \\
\text { - Pérdida de competitividad en costes frente a } \\
\text { competidores extranjeros. } \\
\text { - Reducida dimensión de los establecimientos, } \\
\text { debilitando su poder negociador y reducen sus } \\
\text { canales de venta. } \\
\text { - Dependencia de la coyuntura económica de los } \\
\text { principales países emisores de turistas. }\end{array}$ & $\begin{array}{l}\text { Turismo } \\
\text { - Difícil vertebración del Casco Antiguo. } \\
\text { - Desarrollo de ciudades turísticas cercanas. } \\
\text { - Ausencia de oferta lúdica complementaria a } \\
\text { la cultural. } \\
\text { - Dificultad de extender la oferta turística a } \\
\text { otras } \\
\text { estaciones del año. } \\
\text { - Escasa oferta de servicios de restauración } \\
\text { vinculados a visitantes extranjeros. } \\
\text { - Necesidad de mejora del servicio de las } \\
\text { Oficinas de } \\
\text { Turismo. } \\
\text { - Disminución del gasto medio por turista. } \\
\text { - Dificultades para garantizar el turismo } \\
\text { sostenible. } \\
\text { - Debilidad de la economía y el consumo } \\
\text { debido a la } \\
\text { crisis de } 2007 . \\
\text { - Desarrollo de programas turísticos en países } \\
\text { competidores mediterráneos. }\end{array}$ \\
\hline $\begin{array}{l}\text { Paisaje } \\
\text {-Combinación de buenos paisajes monumentales } \\
\text { y edificios con mala calidad ambiental. } \\
\text { - Paisajes principales deformados por ausencia } \\
\text { de hitos en sombra visual. }\end{array}$ & $\begin{array}{l}\text { Paisaje } \\
\text { - Degradación en entornos patrimoniales o } \\
\text { medioambientales debido a basuras. } \\
\text { - Ausencia de políticas de conservación } \\
\text { medioambiental y del entorno. }\end{array}$ \\
\hline $\begin{array}{l}\text { Ordenación Territorial } \\
\text { - Existencia de áreas degradadas en el Casco } \\
\text { Antiguo. } \\
\text { - Ausencia de ejes de vertebración principales } \\
\text { longitudinales para mejorar la comunicación del } \\
\text { casco antiguo. } \\
\text { - Deficiente interrelación entre distintos tipos de } \\
\text { transporte: terrestre, aéreo y marino. } \\
\text { - Deterioro medioambiental en muchas áreas } \\
\text { de la ciudad, causado por el desordenado } \\
\text { urbanismo y la ausencia de planes de } \\
\text { regeneración. } \\
\text { - Necesidad de mayor coordinación por parte } \\
\text { de las administraciones y asociaciones de la } \\
\text { ciudad. } \\
\text { - Ausencia de líneas estratégicas enfocadas al } \\
\text { futuro del sector relacionando el sector privado } \\
\text { y público. }\end{array}$ & $\begin{array}{l}\text { Ordenación Territorial } \\
\text { - Agresión a bienes patrimoniales o } \\
\text { medioambientales. } \\
\text { - Detrimento de las actividades económicas no } \\
\text { turísticas. } \\
\text { - Falta de inversión en infraestructuras } \\
\text { necesarias para reducir el impacto económico } \\
\text { debido al escaso gasto turístico. } \\
\text { - Escasez de suelo dirigido al sector hotelero. } \\
\text { - Recrudecimiento de la normativa urbanística } \\
\text { y elevado precio en el centro de la ciudad. } \\
\text { - Insuficiente aprovechamiento de las } \\
\text { posibilidades que ofrecen las nuevas } \\
\text { tecnologías de cara a la ordenación urbana de } \\
\text { la ciudad. } \\
\text { - Mala gestión de los Planes Especiales } \\
\text { de Casco Urbano debido a la falta de } \\
\text { coordinación. }\end{array}$ \\
\hline
\end{tabular}




\begin{tabular}{|c|c|}
\hline FORTALEZAS & OPORTUNIDADES \\
\hline $\begin{array}{l}\text { Turismo } \\
\text { - Existencia de importante patrimonio } \\
\text { monumental rehabilitado. } \\
\text { - Oferta turística de sol y playa cerca de la } \\
\text { ciudad. } \\
\text { - Desarrollo de turismo de congresos debido a la } \\
\text { existencia del auditorio y centro de congresos } \\
\text { "El Batel". } \\
\text { - Existencia de un puerto turístico en buenas } \\
\text { condiciones. } \\
\text { - Creciente reconocimiento e importancia del } \\
\text { turismo. } \\
\text { - Atractivo de España como destino turístico y } \\
\text { de negocios. } \\
\text { - Gran oferta gastronómica. } \\
\text { - Presencia creciente en Internet. } \\
\text { - Importante desarrollo del patrimonio cultural } \\
\text { inmaterial. }\end{array}$ & $\begin{array}{l}\text { Turismo } \\
\text { - Creación de nuevas Oficinas Turísticas. } \\
\text { - Puesta en valor de nuevos hallazgos } \\
\text { arqueológicos. } \\
\text { - Construcción de nuevas plazas hoteleras y } \\
\text { servicios de restauración. } \\
\text { - Desarrollo del centro comercial abierto en el } \\
\text { Casco Antiguo. } \\
\text { - Renovación de los servicios por parte de las } \\
\text { administraciones acciones. } \\
\text { - Enfoque progresivo hacia la calidad de } \\
\text { servicios turísticos. } \\
\text { - Búsqueda de nuevos nichos de clientes. }\end{array}$ \\
\hline $\begin{array}{l}\text { Paisaje } \\
\text { - Situación geográfica anexa al mar. }\end{array}$ & $\begin{array}{l}\text { Paisaje } \\
\text { - Entorno en colina de la ciudad convertible en } \\
\text { zonas verdes. } \\
\text { - Políticas de renovación paisajística a través de } \\
\text { lugares de sombra visual. } \\
\text { - Iniciativa empresarial hacia la integración de } \\
\text { políticas de conservación medioambiental y del } \\
\text { entorno. }\end{array}$ \\
\hline $\begin{array}{l}\text { Ordenación Territorial } \\
\text { - Existencia de grupos de desarrollo local. } \\
\text { - Existencia de campus universitarios dentro de } \\
\text { la ciudad (UPCT, UCAM, UNED). } \\
\text { - Reciente apoyo a la dotación de } \\
\text { infraestructuras turísticas. } \\
\text { - Proyectos de la administración local } \\
\text { vinculados con el desarrollo turístico de la } \\
\text { ciudad. }\end{array}$ & $\begin{array}{l}\text { Ordenación Territorial } \\
\text { - Planes Especiales de accesibilidad para } \\
\text { nuevos hallazgos arqueológicos. } \\
\text { - Existencia de un Plan de Excelencia Turística. } \\
\text { - Aumento de la coordinación entre } \\
\text { Asociaciones Públicas y Sector Privado. }\end{array}$ \\
\hline
\end{tabular}

Fuente: Elaboración propia.

Tal y como vemos, la ciudad de Cartagena necesita superar numerosas debilidades y amenazas para prosperar como ciudad turística; a pesar de ello posee gran cantidad de fortalezas para superarlas y consolidarse en el mercado turístico. De cara al turismo existen deficiencias importantes en relación a la falta de vertebración, la necesidad de rehabilitación del patrimonio o la obsolescencia de los servicios lo que provoca una falta de competitividad en relación a otras ciudades turísticas cercanas y que conlleva a ciertas amenazas como la disminución del gasto medio de turistas, la dificultad de sobrepasar la estacionalidad, etc. A pesar de ello la ciudad posee importantes oportunidades debido a la 
existencia de importante patrimonio monumental, o el desarrollo de turismo de congresos o deportivo que genera un atractivo muy importante en la ciudad.

Lo anteriormente dicho se encuentra afectado por el paisaje de la ciudad; se ve afectado por la existencia de importantes lugares con mala calidad ambiental, o deformados por la ausencia de elementos en sombra visual, a pesar de ello en los últimos años están apareciendo políticas de conservación medioambiental que tratan de aprovechar el enclave geográfico de la ciudad debido al apercibimiento de la necesidad de un paisaje bello que influya directamente en la elección de la ciudad. Influyendo tanto al turismo como al paisaje se encuentra la Ordenación Territorial, que se encarga de vincular y desarrollar todo lo anteriormente dicho. Existe una importante ausencia de ejes de vertebración que mejoren la comunicación del casco antiguo, así como una deficiente interrelación de los diferentes medios de transporte a la ciudad, ausencia de suelo dirigido al sector hotelero, un recrudecimiento de la normativa urbanística, etc. actualmente se está logrando una coordinación por parte de la administración con las asociaciones de la ciudad, así como el desarrollo del Planes Especiales del Casco Urbano, o proyectos vinculados al desarrollo turístico de la ciudad, de cara a paliar las deficiencias y fortalecerse en el plano turístico nacional y europeo.

\section{CONCLUSIONES}

Cartagena es una ciudad con un gran potencial turístico que afortunadamente en las últimas décadas ha adquirido conciencia de estas potencialidades y que a través de actuaciones bien desarrolladas están posicionado a la ciudad y su entorno como un importante referente turístico y cultural dentro de la Región de Murcia y del SE español. El análisis cuantitativo ofrecido a través de los datos así como las referencias de percepción efectuadas sobre la influencia del patrimonio en el paisaje, el turismo y la Ordenación Territorial en el Casco Antiguo de Cartagena nos ha permitido llegar a establecer una serie de conclusiones que expondremos a modo de propuestas de actuación y planes de mejora:

1. Aunque ha existido un importante incremento en el número de establecimientos hoteleros en la ciudad, convendría aumentar tanto en el número de establecimientos como en la calidad de los mismos, así como una sustancial mejora en el tiempo de estancia que tiene una media muy baja, inferior a los cuatro días de estancia, lo que repercute en un turismo con poca permanencia en la ciudad y con una importante estacionalidad asentada en los meses de verano.

2. El patrimonio de Cartagena a través de su puesta en valor está sirviendo para revitalizar la ciudad, pero su desarrollo turístico no se ha producido únicamente por la rehabilitación del patrimonio sino también por el acondicionamiento de su entorno urbano, a través de servicios de transporte público, actividades lúdicas, etc.

3. Resulta imprescindible tratar de superar la estacionalidad existente en verano para desarrollar con más fuerza la actividad turística a otras épocas del año. El turismo cultural se ha convertido en una de las principales fuentes de ingreso de Cartagena, así como motor de su desarrollo local en los últimos años.

4. El número de visitantes debido sobre todo al crecimiento del turismo de cruceros ha sido espectacular, no tanto en cantidad de cruceros sino en capacidad de los mismos. Es 
necesario seguir creciendo en este aspecto, para ello la colaboración de tour operadores, y unos precios competitivos serán los mejores aliados en la consolidación de esta modalidad turística novedosa.

5. El Casco Antiguo de la ciudad era un entorno degradado y marginal, pero con el hallazgo del Teatro Romano de Cartagena así como de otros recursos arqueológicos como la puesta en valor del Foro y la renovación de numerosas fachadas modernistas y eclécticas ha dado lugar a la renovación del entorno y la puesta en valor del patrimonio y el paisaje de la ciudad. No obstante todavía permanecen muchas zonas degradadas y de difícil accesibilidad como el entorno del Molinete o la necesaria recuperación del anfiteatro romano todavía sin poner en valor.

6. El turismo cultural se ha convertido en un modelo de desarrollo económico de la ciudad gracias a la gran riqueza patrimonial que posee. La planificación estratégica territorial se ha convertido en un instrumento de desarrollo a partir de numerosas estrategias territoriales para conseguir que la ciudad sea más competitiva con el resto de ciudades turísticas mediterráneas, también convendría incrementar el turismo de congresos a través de las instalaciones existentes en la ciudad como el Auditorium "El Batel" tal como se ha hecho en la ciudad de Murcia (Ponce, 2006).

7. El paisaje de Cartagena es uno de la mayores riquezas de la ciudad, la contemplación desde el Cerro de la Concepción de la ciudad y su puerto es un escenario único de belleza e idiosincrasia de una gran ciudad mediterránea, es necesario seguir creando espacios para la contemplación en otros lugares de la ciudad como las baterías de defensa, el arsenal, Cerro del Molinete o el Puerto.

8. La ciudad de Cartagena no posee espacios para el turismo de Sol y Playa, pero esta modalidad turística queda muy próxima en La Manga y el propio Mar Menor, por tanto es necesaria la conectividad de la ciudad con sus espacios de Playa.

9. La proximidad de otros espacios y modalidades turísticas como sería la Sierra Minera de La Unión-Cartagena, la bahía de Portmán o el Parque Natural de Calblanque, Monte de la Cenizas y Peña del Águila merecen la pena integrarse como una oferta turística, cultural y etnográfica de gran atractivo para Cartagena y su comarca.

10. Cartagena es ciudad de gran oferta gastronómica, la existencia de platos típicos y una importante cadena de establecimientos de restauración que debería ir creciendo suponen un gran complemento para el desarrollo turístico de la ciudad y la creación de empleos estables.

\section{BIBLIOGRAFÍA}

ANDRÉS, J.L. (1982): Cartagena, crecimiento demográfico y desarrollo industrial. Murcia, Imprenta Provincial, $343 \mathrm{pp}$.

ANDRÉS, J.L. (1989) “El diálogo puerto-ciudad en la bahía de Cartagena”. Paralelo 37. $\mathrm{n}^{\mathrm{o}} 13, \mathrm{pp} .7-23$

ANTÓN, S. (2004): “De los procesos de diversificación y cualificación a los productos turísticos emergentes. Cambios y oportunidades en la dinámica reciente del turismo litoral", Papeles de Economía Española, n 102, pp. 316-332. 
AYUNTAMIENTO DE CARTAGENA (2005): Plan Especial de Ordenación y protección del conjunto histórico. Memoria justificativa y explicativa.

BIGNÉ, J.E., FONT, X. y ANDREU, L. (2000): Marketing de destinos turísticos: análisis y estrategias de desarrollo. Madrid, ESIC Editorial.

BOSQUE, J. (1995): "Patrimonio turístico e identidad cultural. El Patrimonio de la Humanidad”. Polígonos, n 5 pp. 173-180.

BUADES, M.L. (2015): "El turismo de cruceros en el Mediterráneo y en las Illes Balears. Un análisis entre el 2000-2012”. Scripta Nova. Revista Electrónica de Geografía y Ciencias Sociales, vol. XIX, $\mathrm{n}^{\circ} 514$.

DE LA CALLE, M y GARCÍA, M. (2016): "Políticas locales de turismo en ciudades históricas españolas. Génesis, evolución y situación actual". Pasos: Revista de Turismo y Patrimonio Cultural, vol. 14 (3), pp. 691-704.

ESPEJO, C. (2008): "El papel de los instrumentos de planificación en las dinámicas productivas y territoriales", en Turismo y desarrollo local. Cuenca, Universidad de Castilla-La Mancha, pp. 161-170.

ESTEVE, J. A., GARCÍA, A. y GUTIÉRREZ, J.E. (2014): Agentes asociados a la configuración de un itinerario de cruceros, hinterland turístico y puertos de crucero en España. Cartagena, Universidad Politécnica de Cartagena. http://repositorio.upct.es/ bitstream/handle/10317/4199/aac.pdf?sequence=1\&isAllowed=y

FORONDA, C. y GARCÍA, A.M. (2009): "La apuesta por la calidad como elemento diferenciador en los destinos turísticos: planes renovados". Cuadernos de Turismo, $\mathrm{n}^{\circ}$ 23, pp. 89-110.

GALIANA, L y BARRADO, D. (2006): “Los Centros de Interés Turístico Nacional y el despegue del turismo de masas en España”. Investigaciones Geográficas, no 39, pp.73-94.

GARAY, L. y CÁNOVES, G. (2012): “Turismo de cruceros en Barcelona. De la marginalidad al liderazgo internacional”, Boletín de la Asociación de Geógrafos Españoles, $\mathrm{n}^{\circ} 60$, pp. 253-272.

GARCÍA, M. (2000): “Turismo y medio ambiente en ciudades históricas de la capacidad de acogida turística a la gestión de los flujos de visitantes", Anales de Geografía de la Universidad Complutense, vol. 20, pp. 131-148.

GARCÍA, N. (2003): "Huellas. Repercusiones del turismo cultural en la Región de Murcia". Cuadernos de Turismo, no 12, pp.119-130.

GONZÁLEZ, G (2012): Evolución y retos del sector hotelero en España. Inédito.

GRANDAL, A. (2010): Historia de Cartagena para principiantes. Cartagena, Ed. Áglaya.

HERRERO, L.C. (2000: “El Patrimonio Histórico o las Riquezas de las Naciones», en Turismo Cultural: El Patrimonio Histórico como Fuente de Riqueza. Valladolid, Fundación Patrimonio Histórico de Castilla y León, p. 17.

ICOMOS: INTERNACIONAL COUNCIL OF MONUMENTS AND SITES (2010): Internacional Charter for tb conservation and restoration of monuments and sites, The Venice Charter, 1964.

MARTÍNEZ, N. (2015): Análisis de la actividad turística en España, la Región de Murcia y el Municipio de Cartagena. Ejercicio comparado a través del Punto Turístico en la Encuesta de Ocupación Hotelera. 
MILLÁN, M. (2014): "Renovación y reposicionamiento de los destinos turísticos. El caso de la ciudad de Cartagena (Murcia)". Gran Tour. Revista de Investigaciones Turísticas, $\mathrm{n}^{\circ} 8$, pp. 85-114

MORALES, F.J. (2016): "La puesta en valor del patrimonio y el paisaje como estrategia para el desarrollo local en Cartagena (Murcia)", en Paisajes culturales a través de casos en España y América. Madrid, Universidad Nacional de Educación a Distancia, pp. 121-168.

MULERO, J.M. (2016): Cartagena como destino turístico: evolución y perspectivas. Inédito.

PARDO, P.J.B., MORA, H.A., y ROJAS, M. (2013): Las estrategias de innovación en empresas del sector cosmético de Bogotá.

PONCE, M.D. (2006): Las administraciones ante el turismo de reuniones y congresos en Murcia. Papeles de Geografía, no 44, pp. 95-118.

SOLER, J (2004): El recinto de Cartagena. Cartagena, Impre. Fotocard.

TROITIÑO, M.A. (2009): "Estrategias de reinvención turística en el grupo de ciudades Patrimonio de la humanidad (Ávila, Salamanca y Segovia) como destinos turísticos de referencia". Polígonos, n 19, pp.145-178.

TROITIÑO. L. (2014). "Estrategias de reinvención turística en el grupo de ciudades Patrimonio de la humanidad”, en F. López y Cánoves (Eds.) Turismo y territorio. Innovación, renovación y desafíos. Valencia, Tirant Humanidades, pp. 295-308

VERA, J.F. (2005): "El auge de la función residencial en destinos turísticos del litoral mediterráneo: entre el crecimiento y la renovación”. Síntesis de la aportación del autor en el I Congreso de Turismo Residencial, organizado en la Universidad de Alicante. Papers de Turisme, $\mathrm{n}^{\circ}$ 37-38, pp. 95-114. 